\title{
Assessing the Jarman-Bell Principle: Scaling of intake, digestibility, retention time and gut fill with body mass in mammalian herbivores
}

\author{
Müller, Dennis W H ; Codron, Daryl ; Meloro, Carlo ; Munn, Adam ; Schwarm, Angela ; Hummel, \\ Jürgen ; Clauss, Marcus
}

\begin{abstract}
Differences in allometric scaling of physiological characters have the appeal to explain species diversification and niche differentiation along a body mass (BM) gradient - because they lead to different combinations of physiological properties, and thus may facilitate different adaptive strategies. An important argument in physiological ecology is built on the allometries of gut fill (assumed to scale to BM1.0) and energy requirements/intake (assumed to scale to BM0.75) in mammalian herbivores. From the difference in exponents, it has been postulated that the mean retention time (MRT) of digesta should scale to BM1.0-0.75 = BM0.25. This has been used to argue that larger animals have an advantage in digestive efficiency and hence can tolerate lower-quality diets. However, empirical data does not support the BM0.25 scaling of MRT, and the deduction of MRT scaling implies, according to physical principles, no scaling of digestibility; basing assumptions on digestive efficiency on the thus-derived MRT scaling amounts to circular reasoning. An alternative explanation considers a higher scaling exponent for food intake than for metabolism, allowing larger animals to eat more of a lower quality food without having to increase digestive efficiency; to date, this concept has only been explored in ruminants. Here, using data for 77 species in which intake, digestibility and MRT were measured (allowing the calculation of the dry matter gut contents DMC), we show that the unexpected shallow scaling of MRT is common in herbivores and may result from deviations of other scaling exponents from expectations. Notably, DMC have a lower scaling exponent than 1.0, and the $95 \%$ confidence intervals of the scaling exponents for intake and DMC generally overlap. Differences in the scaling of wet gut contents and dry matter gut contents confirm a previous finding that the dry matter concentration of gut contents decreases with body mass, possibly compensating for the less favourable volume-surface ratio in the guts of larger organisms. These findings suggest that traditional explanations for herbivore niche differentiation along a BM gradient should not be based on allometries of digestive physiology. In contrast, they support the recent interpretation that larger species can tolerate lower-quality diets because their intake has a higher allometric scaling than their basal metabolism, allowing them to eat relatively more of a lower quality food without having to increase digestive efficiency.
\end{abstract}

DOI: https://doi.org/10.1016/j.cbpa.2012.09.018

Posted at the Zurich Open Repository and Archive, University of Zurich

ZORA URL: https://doi.org/10.5167/uzh-67071

Journal Article

Accepted Version

Originally published at: 
Müller, Dennis W H; Codron, Daryl; Meloro, Carlo; Munn, Adam; Schwarm, Angela; Hummel, Jürgen; Clauss, Marcus (2013). Assessing the Jarman-Bell Principle: Scaling of intake, digestibility, retention time and gut fill with body mass in mammalian herbivores. Comparative Biochemistry and Physiology Part A: Molecular Integrative Physiology, 164(1):129-140.

DOI: https://doi.org/10.1016/j.cbpa.2012.09.018 
1 Assessing the Jarman-Bell Principle: scaling of intake, digestibility, retention time and 2 gut fill with body mass in mammalian herbivores

3

4 Dennis W.H. Müller ${ }^{1,2}$, Daryl Codron ${ }^{1,3}$, Carlo Meloro ${ }^{4}$, Adam Munn ${ }^{5}$, Angela Schwarm ${ }^{6}$, 5 Jürgen $\mathrm{Hummel}^{7}$, Marcus Clauss ${ }^{1 *}$

$7{ }^{1}$ Clinic for Zoo Animals, Exotic Pets and Wildlife, Vetsuisse Faculty, University of Zurich, Winterthurerstr. 260,

$8 \quad 8057$ Zurich, Switzerland, dcodron@vetclinics.uzh.ch, mclauss@ vetclinics.uzh.ch

9 2National Park ‘Bavarian Forest’, Freyungerstr. 2, 94481 Grafenau, Germany, dennis.mueller@npv-

10 bw.bayern.de

$11{ }^{3}$ Florisbad Quaternary Research, National Museum, Bloemfontein, 9300, RSA

$12{ }^{4}$ Center for Anatomical and Human Science, Hull York Medical School, University of Hull, Cottingham Road,

13 Hull HU6 3RX, UK, carlo.meloro@ hyms.ac.uk

$14{ }^{5}$ Institute for Conservation Biology and Environmental Management, School of Biological Sciences, The

15 University of Wollongong, New South Wales 2522 Australia, amunn@uow.edu.au

$16{ }^{6}$ Research Unit Nutritional Physiology ‘Oskar Kellner', Leibniz Institute for Farm Animal Biology (FBN),

17 Wilhelm-Stahl-Allee 2, 18196 Dummerstorf, Germany, schwarm@ fbn-dummerstorf.de

18 7nstitute of Animal Science, University of Bonn, Endenicher Allee 15, 53115 Bonn, Germany, jhum@itw.uni-

19 bonn.de

20

21

22 *to whom correspondence should be addressed

23

24 Running head: Herbivore digestive allometry 


\section{Abstract}

Differences in allometric scaling of physiological characters have the appeal to explain species diversification and niche differentiation along a body mass (BM) gradient - because they lead to different combinations of physiological properties, and thus may facilitate different adaptive strategies. An important argument in physiological ecology is built on the allometries of gut fill (assumed to scale to $\mathrm{BM}^{1.0}$ ) and energy requirements/intake (assumed to scale to $\mathrm{BM}^{0.75}$ ) in mammalian herbivores. From the difference in exponents, it has been postulated that the mean retention time (MRT) of digesta should scale to $\mathrm{BM}^{1.0-0.75}=\mathrm{BM}^{0.25}$. This has been used to argue that larger animals have an advantage in digestive efficiency and hence can tolerate lower-quality diets. However, empirical data does not support the $\mathrm{BM}^{0.25}$ scaling of MRT, and the deduction of MRT scaling implies, according to physical principles, no scaling of digestibility; basing assumptions on digestive efficiency on the thus-derived MRT scaling amounts to circular reasoning. An alternative explanation considers a higher scaling exponent for food intake than for metabolism, allowing larger animals to eat more of a lower quality food without having to increase digestive efficiency; to date, this concept has only been explored in ruminants. Here, using data for 77 species in which intake, digestibility and MRT were measured (allowing the calculation of the dry matter gut contents DMC), we show that the unexpected shallow scaling of MRT is common in herbivores and may result from deviations of other scaling exponents from expectations. Notably, DMC have a lower scaling exponent than 1.0, and the $95 \%$ confidence intervals of the scaling exponents for intake and DMC generally overlap. Differences in the scaling of wet gut contents and dry matter gut contents confirm a previous finding that the dry matter concentration of gut contents decreases with body mass, possibly compensating for the less favourable volumesurface ratio in the guts of larger organisms. These findings suggest that traditional explanations for herbivore niche differentiation along a BM gradient should not be based on allometries of digestive physiology. In contrast, they support the recent interpretation that larger species can tolerate lower-quality diets because their intake has a higher allometric scaling than their basal metabolism, allowing them to eat relatively more of a lower quality food without having to increase digestive efficiency.

Key words: Jarman-Bell Principle; herbivory; body size; diet quality; digestion; allometry; feeding ecology; digestive physiology 
60 The Jarman-Bell Principle

61 The scaling relationships of digestive features with body mass (BM) in herbivores are a fundamental part of our interpretation of herbivore feeding ecology, interspecific niche differentiation and intraspecific niche segregation due to sexual dimorphism. Geist (1974) explained how two PhD studies, which resulted in two publications (Bell, 1971; Jarman, 1974), crystallized an understanding of the ways in which BM affects the ecology of ungulates of the African savannahs. These studies have become the springboard for most analyses of mammal herbivore ecological interactions that include a range of BM (du Toit, 2005). The so-called 'Jarman-Bell Principle' (JBP) (Geist, 1974) has been applied to other animal groups such as primates (Gaulin, 1979), fruit bats (Fleming, 1991) or baleen whales (Tershy, 1992), and predicts that BM constrains nutritional ecology - in terms of the diet quality that larger animals can or must tolerate, as well as their digestive efficiency. That larger animals commonly ingest diets of lower quality has been demonstrated repeatedly (e.g. Owen-Smith, 1988; Codron et al., 2007), and that they often must tolerate poor-quality foods is usually not an issue of debate. This is considered a consequence of large animals' higher absolute food requirements that prevent them from foraging selectively in terms of time constraints, and also a consequence of larger, more 'clumsy' feeding apparatus that again prevents them from foraging selectively in terms of picking out individual food items or plant parts (Owen-Smith, 1988; Shipley, 2007).

A fact often used to explain the increased dietary tolerance (measured as the range in fibre and/or protein content of the diet the animal can tolerate) of larger species are the decreased mass-specific metabolic demands - because the daily requirements for energy (Nagy et al., 1999), nitrogen (Robbins, 1993) and even minerals (Rucker and Storms, 2002) scale to metabolic body mass $\left(\mathrm{BM}^{0.75}\right)$. This scaling effect means that small-bodied species require more energy and nutrients per day and per unit of BM than do large-bodied forms (Geist, 1974). However, without information about the scaling of energy/nutrient intake, knowledge about the scaling of requirements allows no further insight. Concepts about niche diversification along a BM gradient must make an assumption about the difference in scaling between requirement and intake. Given that larger animals ingest lower-quality diets, a similar scaling of intake and requirements would make it necessary that digestive efficiency has a positive scaling, i.e. it should increase with BM. This could be achieved either by selecting a more digestible diet (which violates the assumption of decreasing diet quality), or 
by measures of digestive physiology that increase digestive efficiency, such as prolonged digesta retention. In contrast, if we postulate that there is no scaling of digestive efficiency with $\mathrm{BM}$, then intake would have to scale to $\mathrm{BM}$ at a higher exponent than requirements, in order to compensate for the lower diet quality in larger animals. Historically, the JBP has more often been linked to variation in digestive efficiency than to variation in intake levels.

When developing this approach of the JBP, food intake was, without empirical testing, assumed to scale to body mass in a similar way as animal metabolism (explicitly in Demment, 1983; implicitly in Demment and Van Soest, 1985; note that Van Soest, 1994 does not make an explicit assumption about intake scaling but rests his argument on the scaling of gut fill only). In large datasets, food intake (measured as dry matter intake, DMI, or as gross energy intake) was actually often found to scale to $\mathrm{BM}^{0.75}$ across a wide range of mammalian species (reviewed in Clauss et al., 2007a; Meyer et al., 2010), and thus resembles the scaling of metabolism and requirements. Therefore, the approach that focuses on scaling effects on digestive physiology appears as the logical next step. Including gut fill in these considerations has extended the JBP to specifically comprise not only metabolic scaling, but also digestive physiology. Gut fill (measured as wet matter content, WMC) or dry matter content (DMC) has been suggested to be a constant fraction of BM in herbivores (Parra, 1978; Demment and Van Soest, 1985; Illius and Gordon, 1992; Justice and Smith, 1992; Clauss et al., 2007a). If gut fill actually scales to $\mathrm{BM}^{1.00}$, and food intake scales to $\mathrm{BM}^{0.75}$, these different scaling effects result in a larger gut fill per unit food intake with increasing BM. This should in theory lead to an increase in the time digesta is retained in the gastrointestinal tract (measured as mean retention time, MRT) with increasing BM (Demment and Van Soest, 1985; Illius and Gordon, 1992; Robbins, 1993; McNab, 2002). Explicitly, it is thought that MRT should scale to $\mathrm{BM}^{(1.00-0.75)}=\mathrm{BM}^{0.25}$. Because MRT is positively linked to the digestive efficiency of a herbivore (Foose, 1982; Udén and Van Soest, 1982; Clauss et al., 2007b), this concept has been invoked to postulate that larger herbivores can use food of a lower quality due to a hypothetical capacity for more efficient digestion (Demment and Van Soest, 1985; Illius and Gordon, 1992; Gordon and Illius, 1996). In this way, the JBP delivers an elegant explanation (higher digestive efficiency in larger animals) for a common observation (lower diet quality in larger animals), and represents what may be the most prominent set of allometric considerations in large animal ecology, including theoretical approaches to understanding intraspecific size dimorphism (Short, 1963; Prins and Geelen, 1971; Sinclair, 1977; Hanley 
and Hanley, 1980; Hanley, 1982; Barboza and Bowyer, 2000; du Toit, 2005; Shannon et al., 2006; Woolley et al., 2011).

Empirical evidence for the physiological predictions of the JBP, however, is scarce. While the findings that wet gut contents scale to $\mathrm{BM}^{1.00}$ and food intake scales to $\mathrm{BM}^{0.75}$ are mostly undisputed, digesta retention has repeatedly been shown, in various datasets, not to scale to BM $^{0.25}$ (Clauss et al., 2007a; Clauss et al., 2009; Franz et al., 2011a; Müller et al., 2011; Steuer et al., 2011), with the exception of mammalian caecum fermenters (Clauss et al., 2007a, but see the results of phylogenetically informed statistics in this study down below). Additionally, there is little indication for an increase in digestive efficiency with BM (Justice and Smith, 1992; Wenninger and Shipley, 2000; Pérez-Barbería et al., 2004; Clauss et al., 2009; Steuer et al., 2012). These findings represent a serious conceptual problem for herbivore digestive physiology, because the link between gut fill, food intake and digesta retention is mathematically sound.

\section{Linking digesta retention to gut capacity, food intake and digestibility}

Holleman \& White (1989) provided the underlying equation to this problem, based on the 'Stewart-Hamilton Principle' or the 'Occupancy Principle' (Steele, 1971; Shipley and Clark, 1972), where

$$
\text { indDMC }[\mathrm{kg}]=\text { faecal output }[\mathrm{kg} / \mathrm{h}] * \mathrm{MRT}_{\text {particle }} \mathrm{GIT}[\mathrm{h}]
$$

with indDMC being the indigestible (or undigested) DM content of the whole gastrointestinal tract (GIT), and $\mathrm{MRT}_{\text {particle }}$ GIT the mean retention time of an indigestible particle marker in the whole GIT. Because faecal output is a function of food intake (measured as dry matter intake DMI) and apparent digestibility of dry matter (aD DM) or, in other terms, DMI and the apparent indigestibility of DM (aID DM), we get

$$
\text { faecal output }[\mathrm{kg} / \mathrm{h}]=\mathrm{DMI}[\mathrm{kg} / \mathrm{h}] *(\text { aID DM })
$$

and thus gut fill, food intake and retention time are closely linked as

$$
\text { indDMC }[\mathrm{kg}]=\mathrm{DMI}[\mathrm{kg} / \mathrm{h}] * \operatorname{aID} \mathrm{DM} * \mathrm{MRT}_{\text {particle }} \mathrm{GIT}[\mathrm{h}]
$$

Solving this equation for MRT yields

$$
\mathrm{MRT}_{\text {particle GIT }}[\mathrm{h}]=\text { indDMC }[\mathrm{kg}] /(\mathrm{DMI}[\mathrm{kg} / \mathrm{h}] * \text { aID DM })
$$

Assuming scaling laws for indDMC, DMI and aID DM with body mass with the exponents a, $\mathrm{b}$ and c, respectively, it follows that

$$
\mathrm{MRT}_{\text {particle }} \mathrm{GIT} \sim \mathrm{BM}^{\mathrm{a}} /\left(\mathrm{BM}^{\mathrm{b}} * \mathrm{BM}^{\mathrm{c}}\right) \text { or } \mathrm{MRT}_{\text {particle }} \mathrm{GIT} \sim \mathrm{BM}^{\mathrm{a}-(\mathrm{b}+\mathrm{c})}
$$


159 Under the assumption that indDMC scales as does wet matter contents, i.e. to $\mathrm{BM}^{1.00}$, and

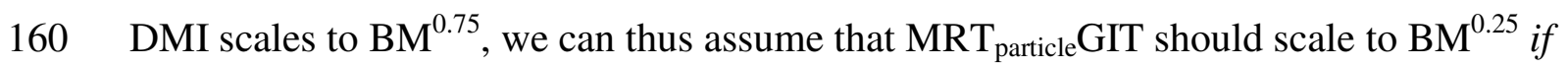

161 digestive efficiency does not change with BM. Note that an increase in digestibility with

162 increasing BM (i.e., a decrease in indigestibility, or a negative exponent c) would lead to a

163 higher scaling exponent for $\mathrm{MRT}_{\text {particle }} \mathrm{GIT}$, and a decrease in digestibility with increasing BM

164 would lead to a lower scaling exponent for $\mathrm{MRT}_{\text {particle }} \mathrm{GIT}$. This is because a lower

165 digestibility would result in more material in the GIT that is pushed along due to the

166 continuous food intake, and hence make any particular portion of the indigestible digesta be

167 excreted relatively sooner (Hummel and Clauss, 2011).

The calculation of gut fill can be expanded to include not only indigestible gut fill, but also total gut fill (dry matter contents DMC) (Holleman and White, 1989). For that, the digestible portion of DMC (dDMC) has to be added to indDMC. To do so, one has to make an assumption regarding the course of digestion. If one assumes digestion to be exponential over MRT (with most of digestion occurring at the beginning of MRT and slowly 'fading out'), then the estimated dDMC in the total GIT will be less than if one assumes digestion to be linear across MRT. Holleman and White (1989) and Munn et al. (2012) showed that assuming a linear course of digestion across MRT yields better results when validated against empirical measures in slaughtered animals, albeit using small sample sizes. Because assuming a linear course of digestion across MRT means that $\mathrm{dDMC}$ is assumed to be present in the GIT during half of MRT, it follows that

Combining equation (3) and (6) to calculate total DMC yields,

$$
\mathrm{DMC}[\mathrm{kg}]=\mathrm{DMI}[\mathrm{kg} / \mathrm{h}] * \mathrm{MRT}_{\text {particle GIT }[\mathrm{h}]} *(\mathrm{aID} \mathrm{DM}+0.5 \mathrm{aD} \mathrm{DM})
$$

Solving the equation for MRT particle $_{\text {GIT }}[\mathrm{h}]$ yields

$$
\mathrm{MRT}_{\text {particle }} \mathrm{GIT}[\mathrm{h}]=\mathrm{DMC}[\mathrm{kg}] / \mathrm{DMI}[\mathrm{kg} / \mathrm{h}] *(1 /(\mathrm{aID} \mathrm{DM}+0.5 \mathrm{aD} \mathrm{DM}))
$$
Assuming scaling laws for DMC, DMI and aD DM with body mass with the exponents d, b and $\mathrm{c}$, respectively, it follows that

$$
\mathrm{MRT}_{\text {particle }} \mathrm{GIT} \sim \mathrm{BM}^{\mathrm{d}} / \mathrm{BM}^{\mathrm{b}} *\left(1 /\left(\mathrm{BM}^{-\mathrm{c}}+0.5 \mathrm{BM}^{\mathrm{c}}\right)\right) \text { or } \mathrm{MRT}_{\text {particle }} \mathrm{GIT} \sim \mathrm{BM}^{\mathrm{d}-\mathrm{b}+\mathrm{c}}
$$

Assuming that DMC scales similar as wet matter contents, i.e. to $\mathrm{BM}^{1.00}$, and DMI scales to

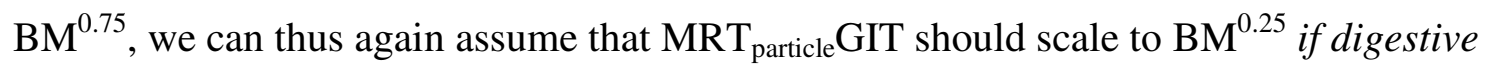
efficiency does not change with BM. Note that again, an increase in digestibility with BM (i.e., a positive c) would lead to a higher scaling exponent for $\mathrm{MRT}_{\text {particle }} \mathrm{GIT}$, and a decrease 
in digestibility with BM would lead to a lower scaling exponent for $\mathrm{MRT}_{\text {particle GIT. One }}$

194 important conclusion from these derivations is that if one uses the scaling of intake and gut

195 fill to make any conclusions about digesta retention, one must not use the result to make inferences about digestive efficiency - because an assumption about the scaling of digestibility is made already (explicitly or implicitly) to derive the scaling of digesta retention. Deriving a scaling for digesta retention in this way and then using it to explain a pattern of digestive efficiency with body mass amounts to circular reasoning.

Re-assessing data from herbivore feeding trials

Given these considerations, a discrepancy in the scaling of gut contents, food intake, and digesta retention, as indicated by empirical data, warrants a re-assessment of both empirical datasets and, potentially, a revision of our understanding of herbivore digestive allometry. An intuitive reason for this discrepancy might be that whereas it is common practice to measure both food intake and digesta retention in the same experiment, gut fill is usually not measured simultaneously, as most experiments do not include the dissection of the experimental animals. The discrepancy of the scaling exponents therefore might simply result from the fact that different datasets have been used to generate these allometries (Clauss et al., 2007a); nevertheless, the discrepancy requires further explanation. If in addition to measures of food intake and digesta retention, the apparent digestibility of dry matter is also measured in the

212 same feeding trial, the derivation of indigestible and complete gut fill (as DMC) as indicated

213 in the equations above is possible. Although this has been done repeatedly in individual 214 studies to compare selected species, or make intraspecific or inter-clade comparisons (Baker 215 and Hobbs, 1987; Gross et al., 1996; Behrend et al., 2004; Munn and Dawson, 2006; Munn and Barboza, 2008; Schwarm et al., 2009a; Clauss et al., 2010b; Franz et al., 2011b; Sawada et al., 2011; Fritz et al., 2012; Munn et al., 2012), a large-scale comparison of mammalian

218 herbivore gut fill has not been performed so far. Therefore, it is the aim of this study to

219 explore the scaling of food intake, digesta retention, apparent digestibility and the calculated 220 gut fill in mammalian herbivores, using available literature data. Because these variables are used to calculate gut fill according to the principles outlined above, we expect that their scaling relationships also follow these principles. 
(i) Across the whole mammal body size range, food intake measured as dry matter intake (DMI) has a scaling exponent close to $\mathrm{BM}^{0.75}$ (reviewed in Clauss et al., 2007a).

Apparent digestibility generally does not scale with body mass (i.e. to $\mathrm{BM}^{0.00}$ ) (Justice and Smith, 1992; Wenninger and Shipley, 2000; Pérez-Barbería et al., 2004; Clauss et al., 2009; Steuer et al., 2012), and therefore the scaling exponents of gut fill $\left(\mathrm{BM}^{\mathrm{a}}\right)$, food intake $\left(\mathrm{BM}^{\mathrm{b}}\right)$ and digesta retention $\left(\mathrm{BM}^{\mathrm{d}}\right)$ are associated according to $d=a-b$. It should be noted, however, that any conclusions concerning the apparent digestibility must be considered in the context of the food sources that were used across experiments. When collating data for a large variety of species from the literature, as we do here, it is highly likely that data from smaller species, which are often kept on artificial feeds for experimental purposes, is combined with data from larger species, which are more often kept on roughage-only diets that are generally less digestible. Thus, a putative negative allometry of digestibility (a decrease with body mass) would be an indication of this uneven distribution of diet quality. How close this potential decrease in diet quality with body size in the dataset actually might resemble the general decrease of diet quality with body size that is supposed to occur in the wild is difficult to judge. Therefore, if scaling is detected between body mass and digestibility, then the

(iii) The low empirical overall scaling exponent for digesta retention (Clauss et al., 2007a; Clauss et al., 2009; Müller et al., 2011; Steuer et al., 2011) results from the fact that gut fill, measured as dry matter contents (DMC), does not scale to $\mathrm{BM}^{1.00}$ but to a lower exponent.

(iv) In parallel to observations on the scaling of mammalian basal metabolic rate (BMR) that does not follow a single exponent across the whole BM range (Clarke et al., 2010; Isaac and Carbone, 2010; Kolokotrones et al., 2010; Müller et al., 2012), we expect that DMI also does not follow one single exponent across the whole $\mathrm{BM}$ range. In fact, variation in the scaling of DMI across the BM range could be responsible for the observation that digesta retention scales differently in different digestion types, which are distributed unevenly across the BM range (Clauss et al., 2007a). In accord with Packard (2012), we do not follow the 
represents a true mechanistic pattern (Kolokotrones et al., 2010), but assume that it is the effect of combined simple scaling patterns in the overall dataset and can be used as a test for such scaling combinations (Müller et al., 2012). A test for such a curvature effect is then followed by analysis of scaling patterns within subsets of the data. In particular, following the dichotomy in metabolism scaling between animals with one and with more than one offspring per litter (Müller et al., 2012), we expect that food intake has a lower scaling exponent in herbivores that represent the majority of the lower BM range (especially caecum fermenters), and a higher scaling exponent in herbivores that represent the majority of the higher $\mathrm{BM}$ range (i.e. non-coprophageous hindgut fermenters, nonruminant foregut fermenters and ruminants), resulting in a typical curvature shape in doublelogarithmic space, or when plotting body mass-residuals of DMI against body mass. An important question when assessing the individual scaling relationships of intake in different groups will be whether the scaling exponent is similar to that of

(v) Differences in the scaling of wet matter gut contents (WMC) and dry matter gut contents (DMC) with BM reflect the finding of Justice and Smith (1992) that larger animals have a higher digesta moisture content; when using the WMC and DMC allometries to calculate the allometry of the dry matter concentration of the GIT contents, the result should be close to that of Justice and Smith (1992) where DM concentration in the contents of the fermentation chamber scales to $22 \mathrm{BM}^{-}$ 0.08

(vi) Species with a relatively higher food intake have a relatively shorter retention time 282 (Clauss et al., 2007a; Müller et al., 2011). Based on the above equation (6), this could in theory lead to relatively lower calculated dry matter gut contents. On the other hand, higher food intake itself should lead to higher calculated gut contents based on the same equation (6). We aim to characterise these interdependencies in our analysis. A longer relative retention time should be related to a higher relative digestibility (Udén et al., 1982; Clauss et al., 2007b).

288 Because one of the largest existing datasets on the digestive physiology of large herbivores 289 (Foose, 1982) is basically incompatible with other published data (Clauss et al., 2007a; Clauss 290 et al., 2010b), we performed the same analyses for both the Foose (1982) dataset and an 291 independent collation of literature data. With the limitation that the Foose (1982) dataset 
comprises only comparatively large species, this allows a corroboration of results from one

293 dataset with the other.

\section{Methods}

The datasets used in this study are

a) Foose (1982), comprising 26 species of large (>100 kg) herbivores from the Artiodactyla, Perissodactyla and Proboscidea, which received two standardized diets (grass and lucerne hay); in this dataset, the unit of reference is organic matter rather than dry matter; and

b) the data collation of Clauss et al. (2007a) that was supplemented with additional sources, and pruned according to the following selection criteria. Only sources were used which gave body mass (BM), dry matter intake (DMI), particle mean retention time in the whole gastrointestinal tract (MRT particle $\mathrm{GIT}$,) and the apparent digestibility of dry matter ( $\mathrm{aD} \mathrm{DM}$ ) from the same experiment (in some cases, this information had to be collected from several publications reporting on the same experiment). From these data, dry matter content (DMC) of the GIT was calculated as outlined in the Indtroduction. For the sake of a large data collection, we did not select publications according to the passage markers used. Therefore, any particle marker was accepted; however, only studies in which small particles (generally $<2 \mathrm{~mm}$; as opposed to whole forages) were labelled were included. Similarly, we did not select publications according to the type of food offered; therefore, the data collection comprises animals fed on a complete, pelleted diet, animals on mixtures of roughages and concentrates, as well as animals on roughage-only diets. Ideally, a data collection with a standardized diet (such as in Foose, 1982; Steuer et al., 2011; 2012) or with diets representing the natural diets of the species would be preferable, but are not available at a larger scale and over a wide body mass range. With regards to some domestic species (rabbits, horse, goats, sheep, cattle), no attempt was made to collate all published data. For lagomorphs and rodents, only data from trials in which coprophagy was not prevented by the study design were used. For each species, one

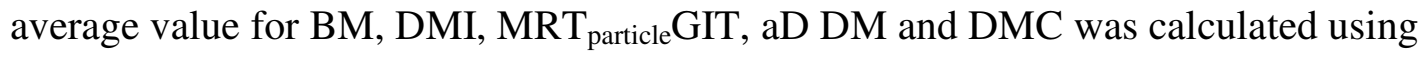
all available data from the cited publications. The data for the resulting 77 mammalian species and its sources are summarized in the Appendix. 
c) To compare the relationship of wet matter contents (WMC) of the GIT with the dry matter contents, the data collection on WMC collated in Clauss et al. (2007a; $n=72$ species) was used.

Species were allocated, according to Stevens and Hume (1995), to one of the following categories: caecum fermenters, colon fermenters, non-ruminant foregut fermenters, and ruminants (Appendix). Additionally, species were allocated to litter size classes (one or more than one offspring per litter) and body size classes $(<10 \mathrm{~kg},>10 \mathrm{~kg})$. In order to account for ancestry-biased correlations in the datasets (i.e., significant associations in interspecific datasets might be due to the fact that phylogenetically related species exhibit similar ecophysiological traits; Harvey and Pagel, 1991), the data were controlled for phylogenetic influences using the "Phylogenetic Generalized Least-Squares" method (PGLS; Martins and Hansen, 1997; Rohlf, 2001). This procedure estimates a covariance matrix of the species due to their ancestral roots and includes these interrelationships as error term in a generalized least squares algorithm to determine the model parameters. The phylogenetic trees for the two datasets were derived by pruning the mammal supertree from Bininda-Emonds et al. (2007, 2008) of those species not represented in the datasets.

Allometric regressions were performed as linear regressions on log-transformed data, with

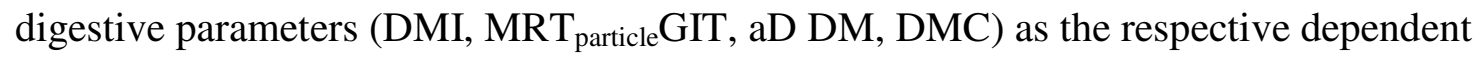
variables, and with log-transformed BM as the independent variable. Tests for a 'curvature' in double-logarithmic space were made using quadratic regressions. Statistical analyses were performed without (ordinary least squares regressions: OLS) and with accounting for phylogeny (PGLS), in PASW 18.0 (SPSS Inc., Chicago, IL) and in $R$ 2.15.0 (Team, 2011) with the caper package. The significance level was set to $\alpha=0.05$.

\section{Results}

Foose (1982) dataset

Variables scaled as: Food intake (as organic matter intake, OMI) with $\mathrm{BM}^{0.76}$, apparent digestibility (of organic matter) with $\mathrm{BM}^{0.02}$, organic matter gut contents (OMC) with $\mathrm{BM}^{0.82}$, and digesta retention with $\mathrm{BM}^{0.07}$, which matches the predicted relationships of $0.07 \sim[0.82-$ $0.76+0.02$ ] (Table 1). Notably, the $95 \%$ confidence interval for the scaling of OMC did not include 1.00 (Table 1). Results were similar in PGLS. Similar patterns were evident within the hindgut fermenters and the ruminants only (Table 1). Both digesta retention and gut fill had a scaling exponent lower than expected. 
359 Within the body mass residuals, intake was negatively correlated with digesta retention in the whole dataset in OLS but not in PGLS (Table 2), indicating that certain taxonomic groups (notably the ruminants) did not follow this pattern (Fig. 1a). Intake was positively correlated with gut fill in both OLS and PGLS (Table 2, Fig. 1b). There was a positive correlation between digesta retention and digestibility in OLS but not in PGLS (Table 2), because these two residuals showed a clear dichotomy between ruminants and colon fermenters (Fig. 1c). Digesta retention was not correlated with gut fill in OLS but it was in PGLS (Table 2), indicating that the relationship only existed within more closely related groups (Fig. 1d).

Our dataset

Variables scaled as: Food intake (as dry matter intake, DMI) with $\mathrm{BM}^{0.76}$ (Fig. 2a), apparent digestibility (of dry matter, aD DM) with $\mathrm{BM}^{-0.03}$ (Fig.2c), dry matter gut contents (DMC) with $\mathrm{BM}^{0.93}$ (Fig. 2e), and digesta retention with $\mathrm{BM}^{0.16}$ (Fig. 2g) (all in OLS), which matches the predicted relationships of $0.16 \sim[0.93-0.76+(-0.03)]$. Notably, the $95 \%$ confidence interval for the scaling of DMC did not include 1.00 (Table 3). Results for PGLS were similar; notably, the scaling exponent for MRT was lower than in OLS at $\mathrm{BM}^{0.12}$.

When testing for a curvature effect in the overall dataset in OLS, such a curvature (visible when plotting body mass residuals against body mass) was evident for dry matter intake (Fig. 2b) and for digesta retention (Fig. 2h), but not for digestibility (Fig. 2d) or gut contents (Fig. 2f). The full term describing the curvature was significant, with $95 \%$ confidence intervals that did not include zero for the quadratic term, for intake and digesta retention only (Table 4); the exponent of the quadratic term had a similar magnitude but a different sign for these two measurements (intake: 0.053, retention: -0.057). In PGLS, these quadratic terms were not significant (Table 4), indicating that the effect of the curvature was caused by the phylogenetic structure of the dataset.

Splitting the overall dataset led to different scaling exponents for the various subsets (Table 5). The scaling of food intake had a lower exponent among species that produce more than one offspring per litter or that are below a $10 \mathrm{~kg}$ threshold (95\%CI 0.57-0.70 in OLS and 0.64-0.81 in PGLS), as opposed to species with one offspring per litter or above the $10 \mathrm{~kg}$ threshold (95\%CI 0.82-0.96 in OLS and 0.74-0.95 in PGLS). The scaling of dry gut contents 
1.00 in the 95\%CI in OLS but for the larger animals in PGLS). In OLS, there was a difference in the scaling of digesta retention between these groups, with a significant scaling exponent in animals with more than one offspring per litter or below the $10 \mathrm{~kg}$ threshold, in contrast to no significant scaling (95\% confidence interval for the exponent included zero) in animals above the $10 \mathrm{~kg}$ threshold (Table 5). In PGLS, the exponent of the MRT scaling in the animals with more than one offspring per litter/below the $10 \mathrm{~kg}$ threshold was distinctively lower than in OLS, with 95\%CI approaching or including zero (Table 5) and thus making the scaling in this group similar to the scaling in the group of animals with one offspring per litter/more than 10 $\mathrm{kg}$. Notably, the $95 \% \mathrm{CI}$ of the scaling exponent of intake and dry gut contents overlapped in animals with a single offspring/animals $>10 \mathrm{~kg}$ in OLS, and for all herbivores in PGLS.

Splitting the species into the four digestion types resulted in similar patterns, with a lower scaling exponent for intake, and a higher one for digesta retention, in the (small) caecum fermenters as compared to the other groups in OLS (Table 6). In PGLS, these differences were not evident; in particular, the scaling exponent for MRT in caecum fermenters was much lower in PGLS at 0.14 than in OLS at 0.27 , suggesting the high scaling previously reported in caecum fermenters of 0.25 (Clauss et al., 2007a) was due to an uneven distribution of phylogenetically distant species within this data subset (Table 6). A scaling exponent of 1.00 for gut fill was only included in the confidence interval for ruminants in OLS, and for colon fermenters and ruminants in PGLS. The 95\% CI of the scaling exponent overlapped for intake and gut fill in all but the caecum fermenters in OLS, and in all four groups in PGLS (Table 6).

Within the body mass residuals of the whole dataset (Table 7), intake was negatively correlated with digesta retention (Fig. 3a) and positively with gut fill (Fig. 3b) in both OLS and PGLS. Although digestibility was negatively related to intake and positively related to digesta retention (Fig. 3c) in OLS, these relationships were not significant in PGLS (Table 7), i.e. they do not occur within more closely related taxa. By contrast, digestibility was negatively related to gut fill in PGLS, indicating that among more closely related species, those with a higher gut fill had lower digestibilities. Gut fill was positively related to digesta retention in both OLS and PGLS (Table 7, Fig. 3d).

\section{Wet gut contents}

When testing for a scaling curvature in the dataset on wet gut contents, the quadratic term was not significant (OLS p=0.706; PGLS p=0.463). Wet gut contents scaled to 0.108 (0.095- 
$0.123) \mathrm{BM}^{1.062(1.029-1.094)}\left(\mathrm{R}^{2}=0.984, \mathrm{p}<0.001\right)$ in OLS and $0.109(0.036-0.332) \mathrm{BM}^{1.086(1.004-}$ 1.167) $\left(\mathrm{R}^{2}=0.907, \mathrm{p}<0.001\right)$ in PGLS. Thus, when comparing the scaling of wet gut contents and of dry matter gut contents, the difference between the two increases with body mass (Fig. 4); from the comparison of the two scaling exponents (OLS 0.93 and 1.06; PGLS 0.92 and 1.09), the dry matter concentration of gut contents should theoretically scale to $\mathrm{BM}^{-0.13}$ or $\mathrm{BM}^{-0.17}$.

\section{Discussion}

The aim of this study was to test whether empirical data allow evoking differences in the allometric scaling between physiological characteristics, to explain species diversification and niche differentiation along a body size gradient in herbivores. Two effects have previously been associated with body size-driven diversification in mammalian herbivores, namely a higher scaling of food intake as compared to the scaling of metabolism (Hackmann and Spain, 2010), and a distinct difference in the scaling of food intake and gut fill, leading to a positive scaling of digesta retention time (Demment and Van Soest, 1985). If we assume that the results of controlled feeding studies are indeed representative of the digestive physiology of the animals investigated, then the results indicate that from these two effects, the former represents the more promising approach, in particular for larger herbivores.

We suggest several reasons for the fact that the concept of an increasing difference between intake and gut fill, and hence increasing digesta retention time with body size, does not apply to herbivores to the extent previously suggested. Indeed, the concept has been questioned repeatedly based on the empirical finding that the expected scaling of digesta retention with body mass cannot be demonstrated (see Introduction). Similarly, the results of our study demonstrate that any scaling of digesta retention, though principally existent, is below the quarter-power scaling often associated with biological times (Illius and Gordon, 1992; Brown et al., 2012). Because of the mathematical relationships between intake, digestibility, retention and gut fill, this translates into the following deviations from the original concept: gut fill does not scale linearly with body mass, but to a slightly lower exponent (the 95\%CI often did not include 1.0); on the other hand, intake scales to an exponent higher than 0.75 in large herbivores. Therefore, the difference between the two scaling exponents is lower than assumed when interpreting the Jarman-Bell principle in terms of digestive physiology, with confidence intervals overlapping in many datasets. Additionally, there is a slight negative 
460

461

462

463

464

465

466

467

468

469

470

471

472

473

474

475

476

477

478

479

480

481

482

483

484

485

486

487

488

489

490

491

492

493

exponent of retention time (see Introduction). The ultimate reason why digesta retention shows a low scaling with body mass in herbivores might stem from the fact that from a certain body size upwards, a further increase in retention time will not, on average, convey additional advantages, principally because the additional gain from exposing digesta to the digestive process for a longer time is lower than the gain from additional food intake (Hummel et al., 2006).

Several arguments can be put forward to support the validity of our findings. The belowlinear scaling of gut contents was present in both of the datasets investigated (Tables 1 and 3). The assumption that gut contents (as a proxy for gut capacity) scale linearly with body mass was originally derived from datasets that related wet gut content mass to body mass (Parra, 1978; Demment and Van Soest, 1985; Justice and Smith, 1992; Clauss et al., 2007a; Illius and Gordon 1992 is the only publication that uses dry matter gut contents and also arrives at linear scaling, but the dataset comprised only 16 species). If one assumes that this finding translates directly into a similar scaling for that unit of gut fill related to food intake (i.e. dry matter), then one makes the silent assumption that the proportion of moisture in gut contents is similar across all body sizes (as done by Demment, 1983). However, Justice and Smith (1992) reported that the DM concentration of the contents of the fermentation chamber scales to $\mathrm{BM}^{-}$ 0.08 - in other words, the contents of this part of the gut becomes more watery in larger animals. Their finding is corroborated by our comparison of the scaling of total wet and dry matter gut contents, which yields a similar negative scaling at $\mathrm{BM}^{-0.13}$ to $\mathrm{BM}^{-0.17}$. Similarly, Müller et al. (2011) found, in a comparative analysis of mean retention times of particle and solute (fluid) markers, that the difference between these two digesta phases tends to increase with body mass - not necessarily because particles are retained longer in larger animals, but also because fluids are passed through their digestive system at a higher rate. One nonexclusive ultimate reason for this might be the fact that in the larger guts of larger animals, diffusion distances from within the digesta to the sites of absorption in the gut wall are increased (Clauss and Hummel, 2005), a problem that could be solved by a more fluid digesta (Lentle et al., 2006). Thus, we suggest that the assumption that that part of gut fill relevant to food intake and digestibility (i.e. the dry matter gut fill) scales linearly with body mass cannot be defended until more data become available.

The other important assumption that is challenged by our findings is that food intake scales uniformly to $\mathrm{BM}^{0.75}$. Unfortunately, a direct inclusion of data on basal metabolic rate (BMR) 
in our study is not feasible; although BMR has been measured in a large variety of mammalian species (McNab, 2008), the large animals that form a majority of our dataset are not included in the available BMR data pool. Therefore, we need to refer to comparisons of our findings to those from BMR studies, inherently with a distinct difference in the species sets investigated. In the debate on the scaling of basal metabolic rate, it has been found repeatedly that across the whole mammalian body mass range, a single allometric exponent does not represent the data very precisely, but that either a curvature in log-log space, or a combination of different scaling relationships of subgroups provides a better fit (Hayssen and Lacy, 1985; Clarke et al., 2010; Isaac and Carbone, 2010; Kolokotrones et al., 2010; Müller et al., 2012). The magnitude of an overall mammalian scaling exponent will therefore depend either on the body mass range included in the analysis (Lovegrove, 2000; Dodds et al., 2001; Glazier, 2005; White and Seymour, 2005), the taxonomic composition of the sample (Hayssen and Lacy, 1985; Sieg et al., 2009; White et al., 2009; Capellini et al., 2010), or on the inclusion of animals according to certain biological characteristics (McNab, 2008; Müller et al., 2012). Although our species sample of mammalian herbivores is lower than the datasets used to investigate the scaling of metabolism, a similar 'curvature effect' is evident in the intake and retention data (Fig. 2ab and 2gh). Our findings thus provide further support to these previous studies that scaling exponents are not necessarily a universal characteristic for the whole mammalian clade, but may differ either between different groups, or vary across the body mass range. In particular, the results indicate that the group of mammals that can be classified as either small, giving birth to multiple young at a time, or being caecum fermenters has a generally lower scaling of food intake than animals classified as larger, giving birth to a single offspring, or being colon fermenters, nonruminant foregut fermenters or ruminants. Which of these classifications is biologically relevant for the difference in scaling, or whether they are all proxies for a yet undefined functional subdivision of mammals, remains to be investigated. Because a similar 'curvature effect' is evident in the scaling of metabolic rate, where not only herbivores but also other feeding types were included in the dataset (Kolokotrones et al., 2010; Müller et al., 2012), we suggest that digestive strategy is unlikely to be the relevant proxy. Regardless, our study suggests that the use of one single exponent to describe relative metabolic rates or relative food intakes may be convenient, but should not be the basis for biological models. scales to $\mathrm{BM}^{0.75}$ has previously been refuted based either on conceptual approaches or 
collections of empirical data: Mertens (1994) and Südekum (2002) explain that for lowquality forages, relating food intake in domestic ruminants to body mass may be more appropriate than using metabolic body mass as the basis. Hackman and Spain (2010) collated data on the voluntary food intake (VFI) in domestic and wild ruminant species in a dataset more comprehensive than ours (that was limited to studies that also measured digestibility and retention), and concluded that VFI scaled to $\mathrm{BM}^{0.9}$, which was similar to that described in previous studies on domestic ruminants (Graham, 1972; Minson, 1990; Reid et al., 1990). The authors concluded that the intermediate scaling between metabolism (0.75) and gut fill (1.0) indicated that both metabolic and physical constraints determine food intake; they also conclude that the putative difference between the scaling of metabolism (0.75) and the scaling of intake (0.9) allows larger animals to ingest lower-quality food and still meet their energetic requirements. Note that this interpretation of scaling differences does not draw on an alleged scaling of digestion efficiency and retention times.

The assumption that intake might scale to a higher exponent than basal metabolic rate is supported when comparing the intake scaling exponent of large herbivores/herbivores with one offspring of this study (0.81-0.89, Table 5) with that of the BMR in mammals with one offspring (0.76; Müller et al. 2012). In contrast, for the small herbivores/herbivores with more than one offspring, such a difference is not evident at 0.62-0.72 for the intake scaling exponent in this study and 0.69 for that of BMR (Müller et al. 2012). To explain body size effects in this group, factors such as variation in feeding selectivity and caecotroph use via coprophagy must be further investigated (Justice and Smith, 1992; Franz et al., 2011b). In particular, it remains unknown whether the proportion of intake achieved via coprophagy varies systematically with body mass. Preliminary results indicate that this proportion increases with increasing dietary fibre content (Takahashi and Sakaguchi, 1998). If we assume that compared to smaller species, larger caecum fermenters are adapted to lowerquality diets (i.e. diets higher in fibre), and should therefore be generally adapted to a higher proportion of intake via coprophagy, this might help explain the lower scaling of intake via food (as measured in the digestion experiments collated in this study) in this group. Further studies that assess the contribution of coprophagy over a wide range of body sizes are required to explore this possibility.

Apart from the logical issue with drawing conclusions on the scaling of digestibility from the scaling of digesta retention explained in the Introduction, our data collection yields some 
562 further insights concerning correlates and effects of digesta retention. As reported previously

563 in inter- and intraspecific analyses (Clauss et al., 2007a; Clauss et al., 2007b; Müller et al.,

564 2011; Steuer et al., 2011), species with a higher relative food intake have comparatively

565 shorter retention times (Fig. 3a). Langer and Snipes (1991) suggested that interspecifically,

566 animals achieve longer digesta retention by higher gut capacities, a concept supported by our

567 findings (Fig. 3b). Additionally, capacity for a higher gut fill will allow a higher food intake

568 (Fig. 3d).

569

570 Although increasing retention times may be associated with higher general digestive

571 efficiencies in intraspecific studies (Clauss et al., 2007b), this effect is most evident in

572 interspecific comparisons in relation to the digestibility of the fibre component of the food

573 (Udén and Van Soest, 1982; Clauss et al., 2009). When comparing the overall diet

574 digestibility, as in this study, where we collated data on the dry matter or organic matter

575 digestibility but not the fibre digestibility, no significant effect of digesta retention on

576 digestibility is evident when accounting for the phylogenetic structure of the data (Table 3 and

577 7). In other words, although larger clades differ systematically in retention and digestibility,

578 such as the colon fermenters and ruminants in Fig. 1c, the effect is not evident among more

579 closely related species - in the case of the Foose (1982) dataset even though consistent diets

580 were used. One potential reason is that digesta retention is not the only determinant of

581 digestibility, but acts together with digesta particle size reduction, either compensating for

582 poor chewing efficiency (as for example in hippopotamuses) or reinforcing a high chewing

583 efficiency (as in the ruminants) (Clauss et al., 2009). Another potential reason is that overall

584 dry matter digestibility does not necessarily reflect fibre digestibility. A small-scale data

585 collection in Clauss and Hummel (2005) suggested that fibre digestibility may vary more

586 across a large herbivore body mass range than does overall diet digestibility, which remained

587 rather constant (as in this study). The authors summarized concepts that interpret these data as

588 indication for a better utilization of non-fibrous food components in smaller animals,

589 including the segregation of bacterial protein during caecotroph formation by the colonic

590 separation mechanism (Björnhag, 1987; Franz et al., 2011b). Understanding how bacterial

591 nitrogen utilization and endogenous/metabolic nitrogen losses vary with body mass and

592 between the different herbivore digestive strategies remains one of the major challenges in

593 studying herbivore digestive physiology (Schwarm et al., 2009b). 
Herbivores will maximize energy intake if they maximize feeding selectivity, food intake and

596 digesta retention (by increasing gut fill), particle size reduction (by more elaborate craniodental designs and by sorting mechanisms in ruminants that increase chewing efficiency), and minimize endogenous/metabolic faecal losses. The major dilemma in this array of factors is that increasing food intake is usually associated with a lower feeding selectivity, shorter digesta retention and reduced particle size reduction (Clauss et al., 2010a). It is commonly assumed that the different herbivore species or groups represent different, equally successful 'digestive strategies' to solve this dilemma, varying in the emphasis of the individual interrelated factors (Hume, 2005). Alternatively, one can hypothesize that the sequence of radiation events in herbivores indicates different levels of optimization of the overall interplay of these factors (Fritz et al., 2009). For example, bovid ruminants, as the most recently radiated large herbivore group, potentially represent the hitherto most sophisticated design that combines high food intakes, long retention times and high chewing efficiency with a very efficient use of the symbiotic microflora (Clauss et al., 2010a; Müller et al., 2011). How species that use similar niches with different digestive strategies can persist then requires different explanations. Such a view shifts the focus in tracing niche differentiation and species diversification from simple allometric considerations to more complex aspects of variation in organismal design.

613

\section{Acknowledgements}

This work was supported by DFG grants CL 182/3-1, 5-1 and 6-1. This is contribution no. 119 of the DFG Research Group 533 Biology of the Sauropod Dinosaurs: The Evolution of Gigantism.

\section{References}

Baker, D.L., Hobbs, N.T., 1987. Strategies of digestion: digestive efficiency and retention times of forage diets in montane ungulates. Can. J. Zool. 65, 1978-1984.

Barboza, P.S., Bowyer, R.T., 2000. Sexual segregation in dimorphic deer: a new gastrocentric hypothesis. J. Mammal. 81, 473-489. gut fill, liquid and particle marker retention in mouflon (Ovis ammon musimon), and a comparison with roe deer (Capreolus capreolus). Acta Theriol. 49, 503-515.

Bell, R.H.V., 1971. A grazing ecosystem in the Serengeti. Sci. Am. 225, 86-93.

Bininda-Emonds, O.R.P., Cardillo, M., Jones, K.E., MacPhee, R.D.E., Beck, R.M.D., Grenyer, R., Price, S.A., Vos, R.A., Gittleman, J.L., Purvis, A., 2007. The delayed rise of 
Bininda-Emonds, O.R.P., Cardillo, M., Jones, K.E., MacPhee, R.D.E., Beck, R.M.D., Grenyer, R., Price, S.A., Vos, R.A., Gittleman, J.L., Purvis, A., 2008. Corrigendum: The delayed rise of present-day mammals. Nature 456, 274.

Björnhag, G., 1987. Comparative aspects of digestion in the hindgut of mammals. The colonic separation mechanism. Dt. tierärztl. Wschr. 94, 33-36.

Brown, J.H., Sibly, R.M., Kodric-Brown, A., 2012. Introduction: metabolism as the basis for a theoretical unification of ecology, in: R.M. Sibly, J.H. Brown, A. Kodric-Brown (Eds.), Metabolic ecology. A scaling approach. Wiley-Blackwell, Chichester, UK, 1-6.

Capellini, I., Venditi, C., Barton, R.A., 2010. Phylogeny and metabolic scaling in mammals. Ecology 91, 2783-2793.

Clarke, A., Rothery, P., Isaac, N.J.B., 2010. Scaling of basal metbolic rate with body mass and temperature in mammals. J. Anim. Ecol. 79, 610-619.

Clauss, M., Hummel, J., 2005. The digestive performance of mammalian herbivores: why big may not be that much better. Mammal Rev. 35, 174-187.

Clauss, M., Schwarm, A., Ortmann, S., Streich, W.J., Hummel, J., 2007a. A case of nonscaling in mammalian physiology? Body size, digestive capacity, food intake, and ingesta passage in mammalian herbivores. Comp. Biochem. Physiol. A 148, 249-265.

Clauss, M., Streich, W.J., Schwarm, A., Ortmann, S., Hummel, J., 2007b. The relationship of food intake and ingesta passage predicts feeding ecology in two different megaherbivore groups. Oikos 116, 209-216.

Clauss, M., Nunn, C., Fritz, J., Hummel, J., 2009. Evidence for a tradeoff between retention time and chewing efficiency in large mammalian herbivores. Comp. Biochem. Physiol. A $154,376-382$.

Clauss, M., Hume, I.D., Hummel, J., 2010a. Evolutionary adaptations of ruminants and their potential relevance for modern production systems. Animal 4, 979-992.

Clauss, M., Lang-Deuerling, S., Müller, D.W.H., Kienzle, E., Steuer, P., Hummel, J., 2010b. Retention of fluid and particles in captive tapirs (Tapirus spp.). Comp. Biochem. Physiol. A $157,95-101$.

Codron, D., Lee-Thorp, J.A., Sponheimer, M., Codron, J., de Ruiter, D., Brink, J.S., 2007. Significance of diet type and diet quality for ecological diversity of African ungulates. J. Anim. Ecol. 76, 526-537.

Demment, M.W., 1983. Feeding ecology and the evolution of body size of baboons. Afr. J. Ecol. 21, 219-233.

Demment, M.W., Van Soest, P.J., 1985. A nutritional explanation for body size patterns of ruminant and nonruminant herbivores. Am. Nat. 125, 641-672.

Dodds, P.S., Rothman, D.H., Weitz, J.S., 2001. Re-examination of the "3/4-law" of metabolism. J. Theor. Biol. 209, 9-27.

du Toit, J.T., 2005. Sex differences in the foraging ecology of large mammalian herbivores, in: K.E. Ruckstuhl, P. Neuhaus (Eds.), Sexual segregation in vertebrates: ecology of the two sexes. Cambridge University Press, New York, 35-52.

Fleming, T.H., 1991. The relationship between body size, diet, and habitat use in frugivorous bats, Genus Carollia (Phyllostomidae). J. Mammal. 72, 493-501.

Foose, T.J., 1982. Trophic strategies of ruminant versus nonruminant ungulates. University of Chicago, Chicago.

Franz, R., Hummel, J., Müller, D.W.H., Bauert, M., Hatt, J.-M., Clauss, M., 2011a. Herbivorous reptiles and body mass: effects on food intake, digesta retention, digestibility and gut capacity, and a comparison with mammals. Comp. Biochem. Physiol. A 158, 94101.

Franz, R., Kreuzer, M., Hummel, J., Hatt, J.-M., Clauss, M., 2011b. Intake, selection, digesta retention, digestion and gut fill of two coprophageous species, rabbits (Oryctolagus 
cuniculus) and guinea pigs (Cavia porcellus), on a hay-only diet. J. Anim. Physiol. Anim. Nutr. 95, 564-570.

Fritz, J., Hummel, J., Kienzle, E., Arnold, C., Nunn, C., Clauss, M., 2009. Comparative chewing efficiency in mammalian herbivores. Oikos 118, 1623-1632.

Fritz, J., Hammer, S., Hebel, C., Arif, A., Michalke, B., Dittmann, M.T., Müller, D.W.H., Clauss, M., 2012. Retention of solutes and different-sized particles in the digestive tract of the ostrich (Struthio camelus massaicus), and a comparison with mammals and reptiles. Comp. Biochem. Physiol. A 163, 56-65.

Gaulin, S.J.C., 1979. A Jarman-Bell model of primate feeding niches. Human Ecology 7, 120.

Geist, V., 1974. On the relationship of social evolution and ecology in ungulates. American Zoology 14, 205-220.

Glazier, D.S., 2005. Beyond the '3/4-power law': variation in the intra- and interspecific scaling of metabolic rate in animals. Biol. Rev. 80, 1-52.

Gordon, I.J., Illius, A.W., 1996. The nutritional ecology of African ruminants: a reinterpretation. J. Anim. Ecol. 65, 18-28.

Graham, N.M., 1972. Units of metabolic body size for comparisons amongst adult sheep and cattle. Proceedings of the Australian Society of Animal Production 9, 352-355.

Gross, J.E., Alkon, P.U., Demment, M.W., 1996. Nutritional ecology of dimorphic herbivores: digestion and passage rates in Nubian ibex. Oecologia 107, 170-178.

Hackmann, T.J., Spain, J.N., 2010. Ruminant ecology and evolution: Perspectives useful to ruminant livestock research and production. J. Dairy Sci. 93, 1320-1334.

Hanley, T.A., Hanley, K.A., 1980. Food resource partitioning by sympatric ungulates on Great Basin rangeland. J. Range Manage. 35, 152-158.

Hanley, T.A., 1982. The nutritional basis for food selection by ungulates. J. Range Manage. $35,146-151$.

Harvey, P.H., Pagel, M.D., 1991. The comparative method in evolutionary biology. Oxford University Press, Oxford.

Hayssen, V., Lacy, R.C., 1985. Basal metabolic rates in mammals: taxonomic differences in the allometry of BMR and body mass. Comp. Biochem. Physiol. A 81, 741-754.

Holleman, D.F., White, R.G., 1989. Determination of digesta fill and passage rate from non absorbed particulate phase markers using the single dosing method. Can. J. Zool. 67, 488494.

Hume, I.D., 2005. Concepts of digestive efficiency, in: J.M. Starck, T. Wang (Eds.), Physiological and ecological adaptations to feeding in vertebrates. Science Publishers, Enfield NH, 43-58.

Hummel, J., Südekum, K.-H., Streich, W.J., Clauss, M., 2006. Forage fermentation patterns and their implications for herbivore ingesta retention times. Funct. Ecol. 20, 989-1002.

Hummel, J., Clauss, M., 2011. Feeding and digestive physiology, in: N. Klein, K. Remes, C.T. Gee, M. Sander (Eds.), Understanding the life of giants. The biology of the sauropod dinosaurs. Indiana University Press, Bloomington, 11-33.

Illius, A.W., Gordon, I.J., 1992. Modelling the nutritional ecology of ungulate herbivores: evolution of body size and competitive interactions. Oecologia 89, 428-434.

Isaac, N.J.B., Carbone, C., 2010. Why are metabolic scaling exponents so controversial? Quantifying variance and testing hypotheses. Ecol. Lett. 13, 728-735.

Jarman, P.J., 1974. The social organization of antelope in relation to their ecology. Behaviour 48, 215-266.

Justice, K.E., Smith, F.A., 1992. A model of dietary fiber utilization by small mammalian herbivores, with empirical results for Neotoma. Am. Nat. 139, 398-416.

Kolokotrones, T., Savage, V.M., Deeds, E.J., Fontana, W., 2010. Curvature in metabolic scaling. Nature 464, 753-756. 
Langer, P., Snipes, R.L., 1991. Adaptations of gut structure to function in herbivores, in: T.

Tsuda, Y. Sasaki, R. Kawashima (Eds.), Physiological aspects of digestion and metabolism in ruminants. Academic Press, San Diego, 349-384.

Lentle, R., Hemar, Y., Hall, C., 2006. Viscoelastic behaviour aids extrusion from and reabsorption of the liquid phase into the digesta plug: creep rheometry of hindgut digesta in the common brushtail possum Trichosurus vulpecula. J. Comp. Physiol. B 176, 469475.

Lovegrove, B.G., 2000. The zoogeography of mammalian basal metabolic rate. Am. Nat. 156, 201-219.

Martins, E.P., Hansen, T.F., 1997. Phylogenies and the comparative method: a general approach to incorporating phylogenetic information into analysis of interspecific data. Am. Nat. 149, 646-667.

McNab, B.K., 2002. The physiological ecology of vertebrates. A view from energetics. Cornell University Press, Ithaca \& London.

McNab, B.K., 2008. An analysis of the factors that influence the level and scaling of mammalian BMR. Comp. Biochem. Physiol. A 151, 5-28.

Mertens, D.R., 1994. Regulation of forage intake, in: G.C. Fahey, M. Collins, D.R. Mertens, L.E. Moser (Eds.), Forage quality, evaluation, and utilization. American Society of Agronomy, Madison, WI, 450-493.

Meyer, K., Hummel, J., Clauss, M., 2010. The relationship between forage cell wall content and voluntary food intake in mammalian herbivores. Mammal Rev. 40, 221-245.

Minson, D.J., 1990. Forage in ruminant nutrition. Academic Press, London.

Müller, D.W.H., Caton, J., Codron, D., Schwarm, A., Lentle, R., Streich, W.J., Hummel, J., Clauss, M., 2011. Phylogenetic constraints on digesta separation: variation in fluid throughput in the digestive tract in mammalian herbivores. Comp. Biochem. Physiol. A 160, 207-220.

Müller, D.W.H., Codron, D., Werner, J., Fritz, J., Hummel, J., Griebeler, E.M., Clauss, M., 2012. Dichotomy of eutherian reproduction and metabolism. Oikos 121, 102-115.

Munn, A.J., Dawson, T.J., 2006. Forage fibre digestion, rates of feed passage and gut fill in juvenile and adult red kangaroos (Macropus rufus): why body size matters. J. Exp. Biol. 209, 1535-1547.

Munn, A.J., Barboza, P.S., 2008. Could a big gut be too costly for muskoxen (Ovibos moschatus) in their first winter? Zoology 111, 350-362.

Munn, A.J., Tomlinson, S., Savage, T., Clauss, M., 2012. Retention of different-sized particles and derived gut fill estimate in tammar wallabies (Macropus eugenii): physiological and methodological considerations. Comp. Biochem. Physiol. A 161, $243-$ 249.

Nagy, K.A., Girard, I.A., Brown, T.K., 1999. Energetics of free-ranging mammals, reptiles, and birds. Ann. Rev. Nutr. 19, 247-277.

Owen-Smith, N., 1988. Megaherbivores - the influence of very large body size on ecology. Cambridge University Press, Cambridge.

Packard, G.C., 2012. Is non-loglinear allometry a statistical artifact? Biol. J. Linn. Soc. (online).

Parra, R., 1978. Comparison of foregut and hindgut fermentation in herbivores, in: G.G. Montgomery (Ed.), The ecology of arboreal folivores. Smithsonian Institution Press, Washington DC, 205-229.

Pérez-Barbería, F.J., Elston, D.A., Gordon, I.J., Illius, A.W., 2004. The evolution of phylogenetic differences in the efficiency of digestion in ruminants. Proc. R. Soc. B 271, 1081-1090.

Prins, R.A., Geelen, M.J.H., 1971. Rumen characteristics of red deer, fallow deer and roe deer. J. Wildl. Manage. 35, 673-680. 
801

802

803

804

805

806

807

808

809

810

811

812

813

814

815

816

817

818

819

820

821

822

823

824

825

826

827

828

829

830

831

832

833

Reid, R.L., Jung, G.A., Cox-Ganser, J.M., Rybeck, B.F., Townsend, E.C., 1990. Comparative utilization of warm-and cool-season forages by cattle, sheep and goats. J. Anim. Sci. 68, 2986-2994.

Robbins, C.T., 1993. Wildlife feeding and nutrition. Academic Press, San Diego.

Rohlf, F., 2001. Comparative methods for the analysis of continuous variables: geometric interpretations. Evolution 55, 2143-2160.

Rucker, R., Storms, D., 2002. Interspecies comparisons of micronutrient requirements: metabolic vs. absolute body size. J. Nutr. 132, 2999-3000.

Sawada, A., Sakaguchi, E., Hanya, G., 2011. Digesta passage time, digestibility, and total gut fill in captive Japanese macaques (Macaca fuscata): effects food type and food intake level. Int. J. Primatol. 32, 390-405.

Schwarm, A., Ortmann, S., Wolf, C., Streich, W.J., Clauss, M., 2009a. More efficient mastication allows increasing intake without compromising digestibility or necessitating a larger gut: comparative feeding trials in banteng (Bos javanicus) and pygmy hippopotamus (Hexaprotodon liberiensis). Comp. Biochem. Physiol. A 152, 504-512.

Schwarm, A., Schweigert, M., Ortmann, S., Hummel, J., Janssens, G., Streich, W.J., Clauss, M., 2009b. No easy solution for the fractionation of faecal nitrogen in captive wild herbivores: results of a pilot study. J. Anim. Physiol. Anim. Nutr. 93, 596-605.

Shannon, G., Page, B., Duffy, K., Slotow, R., 2006. The role of foraging behaviour in the sexual segregation of the African elephant. Oecologia 150, 344-354.

Shipley, L.A., 2007. The influence of bite size on foraging at larger spatial and temporal scales by mammalian herbivores. Oikos 116, 1964-1974.

Shipley, R.A., Clark, R.E., 1972. Tracer methods for in vivo kinetics. Academic Press, New York.

Short, H.L., 1963. Rumen fermentation and energy relationships in the white-tailed deer. J. Wildl. Manage. 28, 445-458.

Sieg, A.E., O'Connor, M.P., McNair, J.N., Grant, B.W., Agosta, S.J., Dunham, A.E., 2009. Mammalian metabolic allometry: do intraspecific variation, phylogeny, and regression models matter? Am. Nat. 174, 720-733.

Sinclair, A.R.E., 1977. The African buffalo: a study of resource limitation of populations. University of Chicago Press, Chicago.

Steele, R., 1971. Tracer probes in steady state systems. Charles C. Thomas Publisher, Springfield IL.

Steuer, P., Südekum, K.-H., Müller, D.W.H., Franz, R., Kaandorp, J., Clauss, M., Hummel, J., 2011. Is there an influence of body mass on digesta mean retention time in herbivores? A comparative study on ungulates. Comp. Biochem. Physiol. A 160, 355-364.

Steuer, P., Südekum, K.-H., Müller, D.W.H., Kaandorp, J., Clauss, M., Hummel, J., 2012. Fibre digestibility in large herbivores as related to digestion type and body mass - an in vitro approach. (submitted).

Stevens, C.E., Hume, I.D., 1995. Comparative physiology of the vertebrate digestive system. Cambridge University Press, New York.

Südekum, K.-H., 2002. Technical basis of international feed evaluation systems for dairy cows and future prostpects for the German recommendations (energy, protein and amino acids). Übersichten Tierernährung 30, 135-162.

Takahashi, T., Sakaguchi, E., 1998. Behaviors and nutritional importance of coprophagy in captive adult and young nutrias (Myocastor coypus). J. Comp. Physiol. B 168, 281-288.

Team, R.D.C., 2011. R: A language and environment for statistical computing. R Foundation for Statistical Computing, Vienna, Austria. ISBN 3-900051-07-0, URL http://www.Rproject.org/.

Tershy, B.R., 1992. Body size, diet, habitat use, and social behavior of balaenoptera whales in the Gulf of California. J. Mammal. 73, 477-486 
834 Udén, P., Rounsaville, T.R., Wiggans, G.R., Van Soest, P.J., 1982. The measurement of 835 liquid and solid digesta retention in ruminants, equines and rabbits given timothy (Phleum 836 pratense) hay. Br. J. Nutr. 48, 329-339.

837 Udén, P., Van Soest, P.J., 1982. Comparative digestion of timothy fiber by ruminants, equines and rabbits. Br. J. Nutr. 47, 267-272.

Van Soest, P.J., 1994. Nutritional ecology of the ruminant, 2nd ed. Cornell University Press, Ithaca.

Wenninger, P.S., Shipley, L.A., 2000. Harvesting, rumination, digestion, and passage of fruit and leaf diets by a small ruminant, the blue duiker. Oecologia 123, 466-474.

White, C.R., Seymour, R.S., 2005. Allometric scaling of mammalian metabolism. J. Exp. Biol. 208, 1611-1619.

White, C.R., Blackburn, T.M., Seymour, R.S., 2009. Phylogenetically informed analysis of the allometry of mammalian basal metabolic rate supports neither geometric nor quarterpower scaling. Evolution 63, 2658-2667.

850

851

Woolley, L.-A., Page, B., Slotow, R., 2011. Foraging strategy within African elephant family units: Why body size matters. Biotropica 43, 489-495. 
853 Table 1. Scaling relationships of parameters of digestive physiology with body mass (BM) in 854 the Foose (1982) dataset using OLS and PGLS statistics according to $\mathrm{y}=\mathrm{a} \mathrm{BM}^{\mathrm{b}}$.

\begin{tabular}{|c|c|c|c|c|c|c|c|}
\hline $\mathbf{y}$ & stats & $\mathbf{a}$ & $95 \% \mathrm{CI}$ & b & $95 \% \mathrm{CI}$ & $\mathbf{r}^{2}$ & $\mathbf{p}$ \\
\hline \multicolumn{8}{|c|}{ all species $(n=26)$} \\
\hline OMI & \multirow{4}{*}{ OLS } & 0.064 & $0.027-0.153$ & 0.759 & $0.621-0.897$ & 0.843 & $<0.001$ \\
\hline aDOM & & 53.6 & $40.6-70.6$ & 0.015 & $-0.029-0.059$ & 0.020 & 0.494 \\
\hline OMC & & 0.074 & $0.038-0.147$ & 0.819 & $0.710-0.927$ & 0.910 & $<0.001$ \\
\hline MRT & & 38.2 & $22.2-65.6$ & 0.065 & $-0.020-0.151$ & 0.094 & 0.128 \\
\hline OMI & \multirow{4}{*}{ PGLS } & 0.052 & $0.024-0.114$ & 0.792 & $0.690-0.895$ & 0.905 & $<0.001$ \\
\hline aDOM & & 45.7 & $34.7-60.2$ & 0.033 & $-0.004-0.069$ & 0.115 & 0.062 \\
\hline OMC & & 0.063 & $0.025-0.161$ & 0.842 & $0.719-0.964$ & 0.883 & $<0.001$ \\
\hline MRT & & 37.3 & $21.6-64.5$ & 0.062 & $-0.010-0.134$ & 0.107 & 0.075 \\
\hline \multicolumn{8}{|c|}{ Hindgut fermenter $(\mathrm{n}=11)$} \\
\hline OMI & \multirow{4}{*}{ OLS } & 0.097 & $0.034-0.281$ & 0.726 & $0.564-0.888$ & 0.920 & $<0.001$ \\
\hline $\mathrm{aDOM}$ & & 46.5 & $36.1-59.7$ & 0.024 & $-0.015-0.062$ & 0.180 & 0.194 \\
\hline OMC & & 0.085 & $0.037-0.196$ & 0.809 & $0.681-0.937$ & 0.958 & $<0.001$ \\
\hline MRT & & 27.1 & $16.9-43.6$ & 0.092 & $0.019-0.164$ & 0.477 & 0.019 \\
\hline OMI & \multirow{4}{*}{ PGLS } & 0.083 & $0.029-0.242$ & 0.748 & 0.597-0.899 & 0.913 & $<0.001$ \\
\hline $\mathrm{aDOM}$ & & 37.1 & $26.9-51.3$ & 0.054 & $0.008-0.099$ & 0.375 & 0.029 \\
\hline $\mathrm{OMC}$ & & 0.074 & $0.026-0.208$ & 0.824 & $0.679-0.970$ & 0.932 & $<0.001$ \\
\hline MRT & & 25.2 & $14.9-42.8$ & 0.098 & $0.023-0.172$ & 0.425 & 0.017 \\
\hline \multicolumn{8}{|c|}{ Ruminant (n=13) } \\
\hline OMI & \multirow{4}{*}{ OLS } & 0.104 & $0.029-0.372$ & 0.664 & $0.452-0.875$ & 0.813 & $<0.001$ \\
\hline aDOM & & 52.1 & $33.8-80.2$ & 0.031 & $-0.040-0.103$ & 0.079 & 0.353 \\
\hline $\mathrm{OMC}$ & & 0.126 & $0.028-0.581$ & 0.728 & $0.476-0.980$ & 0.786 & $<0.001$ \\
\hline MRT & & 39.3 & $17.1-89.7$ & 0.079 & $-0.058-0.216$ & 0.128 & 0.231 \\
\hline OMI & \multirow{4}{*}{ PGLS } & 0.099 & $0.034-0.283$ & 0.665 & $0.504-0.825$ & 0.857 & $<0.001$ \\
\hline aDOM & & 67.2 & $43.8-103.0$ & -0.010 & $-0.075-0.055$ & 0.008 & 0.911 \\
\hline $\mathrm{OMC}$ & & 0.165 & $0.037-0.737$ & 0.687 & $0.460-0.915$ & 0.761 & $<0.001$ \\
\hline MRT & & 61.0 & $23.7-156.9$ & 0.016 & $-0.128-0.160$ & 0.004 & 0.954 \\
\hline
\end{tabular}

855

856

857

858

859

860

861

Table 2. Correlations between body mass residuals of parameters of digestive physiology in all species of the Foose (1982) dataset analysed by OLS and PGLS statistics (differences indicated by grey shading).

\begin{tabular}{lllll}
\hline & stats & Residual aDOM & Residual OMC & Residual MRT \\
\hline Residual OMI & OLS & $\mathrm{R}=-0.137, \mathrm{p}=0.505$ & $\mathrm{R}=0.841, \mathrm{p}<0.001$ & $\mathrm{R}=-0.577, \mathrm{p}=0.002$ \\
& PGLS & $\mathrm{R}=-0.300, \mathrm{p}=0.114$ & $\mathrm{R}=0.828, \mathrm{p}<0.001$ & $\mathrm{R}=0.033, \mathrm{p}=0.975$ \\
Residual aDOM & OLS & & $\mathrm{R}=0.173, \mathrm{p}=0.398$ & $\mathrm{R}=0.654, \mathrm{p}<0.001$ \\
& PGLS & $\mathrm{R}=0.297, \mathrm{p}=0.120$ & $\mathrm{R}=0.293, \mathrm{p}=0.126$ \\
\multirow{2}{*}{ Residual OMC } & OLS & & & $\mathrm{R}=-0.055, \mathrm{p}=0.790$ \\
& PGLS & & & $\mathrm{R}=0.575, \mathrm{p}<0.001$ \\
\hline
\end{tabular}


866 Table 3. Scaling relationships of parameters of digestive physiology with body mass (BM) in 867 the dataset of this study ( $\mathrm{n}=77$ ) using OLS and PGLS statistics according to $\mathrm{y}=\mathrm{a} \mathrm{BM}^{\mathrm{b}}$.

\begin{tabular}{lcrccccr}
\hline \multicolumn{1}{c}{$\mathbf{y}$} & stats & \multicolumn{1}{c}{$\mathbf{a}$} & $\mathbf{9 5 \%} \mathbf{C I}$ & $\mathbf{b}$ & $\mathbf{9 5 \%} \mathbf{C I}$ & $\mathbf{r}^{\mathbf{2}}$ & \multicolumn{1}{c}{$\mathbf{p}$} \\
\hline DMI & & 0.046 & $0.041-0.052$ & 0.763 & $0.732-0.794$ & 0.970 & $<0.001$ \\
aDDM & & 65.5 & $61.9-69.2$ & -0.025 & $-0.039--0.011$ & 0.147 & 0.001 \\
DMC & OLS & 0.029 & $0.025-0.032$ & 0.931 & $0.902-0.960$ & 0.982 & $<0.001$ \\
MRT & & 22.3 & $19.5-25.5$ & 0.158 & $0.124-0.191$ & 0.540 & $<0.001$ \\
& & & & & & & \\
DMI & & 0.039 & $0.017-0.089$ & 0.773 & $0.720-0.825$ & 0.916 & $<0.001$ \\
aDDM & & 67.8 & $42.3-108.6$ & -0.052 & $-0.082--0.021$ & 0.130 & $<0.001$ \\
DMC & PGLS & 0.028 & $0.010-0.075$ & 0.915 & $0.851-0.979$ & 0.913 & $<0.001$ \\
MRT & & 26.1 & $11.639-58.4$ & 0.120 & $0.068-0.172$ & 0.214 & $<0.001$ \\
\hline
\end{tabular}

dry matter intake (DMI in $\left.\mathrm{kg} \mathrm{d}^{-1}\right)$; apparent digestibility of dry matter (aDDM in \%); dry matter gut contents (DMC in kg); particle mean retention time (MRT in h)

870

871

Table 4. Evidence for quadratic scaling in parameters of digestive physiology with body mass $(\mathrm{BM})$ in the dataset of this study $(\mathrm{n}=77)(\mathrm{OLS})$. Linear regression models according to

$874 \log \mathrm{y}=\mathrm{a}+\mathrm{b} 1(\log \mathrm{BM})+\mathrm{b} 2\left((\log \mathrm{BM})^{2}\right)$ or $\mathrm{y}=\mathrm{a} \mathrm{BM}^{(\mathrm{b} 1+\mathrm{b} 2(\log \mathrm{BM}))}$

\begin{tabular}{|c|c|c|c|c|c|c|c|c|c|}
\hline $\mathbf{y}$ & stats & $\mathbf{a}$ & $95 \%$ CI & b1 & $95 \% \mathrm{CI}$ & b2 & $95 \% \mathrm{CI}$ & R2 (adj.) & p \\
\hline DMI & & 0.042 & $0.038-0.047$ & 0.659 & 0.616-0.702 & 0.053 & 0.035-0.070 & $0.980(0.979)$ & $<0.001$ \\
\hline aDDM & OI $\mathrm{S}$ & 66.7 & $63.1-70.5$ & -0.004 & $-0.027-0.018$ & -0.010 & -0.019--0.001 & $0.202(0.181)$ & $<0.001$ \\
\hline DMC & ULS & 0.028 & $0.025-0.032$ & 0.930 & 0.881-0.979 & 0.001 & $-0.019-0.021$ & $0.982(0.981)$ & $<0.001$ \\
\hline MRT & & 24.7 & $22.0-27.7$ & 0.270 & 0.223-0.316 & -0.057 & $-0.076--0.038$ & $0.692(0.983)$ & $<0.001$ \\
\hline DMI & & 0.039 & $0.018-0.088$ & 0.706 & $0.617-0.795$ & 0.026 & $-0.002-0.054$ & $0.920(0.918)$ & $<0.001$ \\
\hline aDDM & & 67.7 & 42.1-108.9 & -0.056 & $-0.108--0.003$ & 0.001 & $-0.015-0.018$ & $0.130(0.106)$ & 0.002 \\
\hline DMC & PGLS & 0.028 & $0.010-0.074$ & 0.851 & $0.743-0.959$ & 0.025 & $-0.009-0.060$ & $0.915(0.913)$ & $<0.001$ \\
\hline MRT & & 26.1 & 11. $6-58.7$ & 0.121 & $0.032-0.211$ & -0.001 & $-0.029-0.028$ & $0.214(0.193)$ & $<0.001$ \\
\hline
\end{tabular}


879 Table 5. Scaling relationships of parameters of digestive physiology with body mass (BM) in 880 the dataset of this study in subsets according to litter size or a $10 \mathrm{~kg}$ body mass threshold

881 using OLS and PGLS statistics according to $\mathrm{y}=\mathrm{a} \mathrm{BM}^{\mathrm{b}}$.

\begin{tabular}{|c|c|c|c|c|c|c|c|}
\hline $\mathbf{y}$ & stats & $\mathbf{a}$ & $95 \% \mathrm{CI}$ & b & $95 \% \mathrm{CI}$ & $\mathbf{r}^{2}$ & $\mathbf{p}$ \\
\hline \multicolumn{8}{|c|}{ Litter size $>1(n=24)$} \\
\hline DMI & \multirow{4}{*}{ OLS } & 0.050 & $0.046-0.055$ & 0.663 & $0.626-0.701$ & 0.984 & $<0.001$ \\
\hline aDDM & & 62.230 & $57.4-67.3$ & -0.023 & $-0.054-0.008$ & 0.095 & 0.142 \\
\hline DMC & & 0.027 & $0.022-0.034$ & 0.905 & $0.825-0.986$ & 0.961 & $<0.001$ \\
\hline MRT & & 19.275 & $16.0-23.2$ & 0.233 & $0.160-0.307$ & 0.662 & $<0.001$ \\
\hline DMI & \multirow{4}{*}{ PGLS } & 0.047 & $0.032-0.067$ & 0.724 & $0.647-0.802$ & 0.938 & $<0.001$ \\
\hline $\mathrm{aDDM}$ & & 64.3 & $50.7-81.6$ & -0.015 & $-0.066-0.035$ & 0.015 & 0.712 \\
\hline DMC & & 0.028 & $0.014-0.058$ & 0.884 & $0.733-1.036$ & 0.856 & $<0.001$ \\
\hline MRT & & 21.8 & $12.6-37.9$ & 0.153 & $0.036-0.270$ & 0.230 & 0.006 \\
\hline \multicolumn{8}{|c|}{ Litter size $=1(n=53)$} \\
\hline DMI & \multirow{4}{*}{ OLS } & 0.029 & $0.024-0.036$ & 0.864 & $0.818-0.910$ & 0.966 & $<0.001$ \\
\hline $\mathrm{aDDM}$ & & 72.611 & $65.9-80.0$ & -0.046 & $-0.067--0.024$ & 0.260 & $<0.001$ \\
\hline DMC & & 0.028 & $0.023-0.035$ & 0.935 & $0.891-0.978$ & 0.973 & $<0.001$ \\
\hline MRT & & 36.475 & $30.3-44.1$ & 0.051 & $0.009-0.093$ & 0.105 & 0.018 \\
\hline DMI & \multirow{4}{*}{ PGLS } & 0.030 & $0.013-0.074$ & 0.814 & $0.747-0.881$ & 0.917 & $<0.001$ \\
\hline $\mathrm{aDDM}$ & & 67.0 & $45.0-99.8$ & -0.040 & $-0.071--0.010$ & 0.117 & 0.002 \\
\hline DMC & & 0.026 & $0.010-0.070$ & 0.916 & $0.841-0.990$ & 0.919 & $<0.001$ \\
\hline MRT & & 31.5 & $14.1-70.2$ & 0.084 & $0.023-0.145$ & 0.125 & 0.002 \\
\hline \multicolumn{8}{|c|}{$<10 \mathrm{~kg}(\mathrm{n}=36)$} \\
\hline DMI & \multirow{4}{*}{ OLS } & 0.045 & $0.040-0.050$ & 0.622 & $0.568-0.677$ & 0.941 & $<0.001$ \\
\hline aDDM & & 67.453 & $64.3-70.8$ & 0.020 & $-0.005-0.045$ & 0.070 & 0.119 \\
\hline DMC & & 0.028 & $0.024-0.032$ & 0.909 & $0.834-0.984$ & 0.947 & $<0.001$ \\
\hline MRT & & 22.751 & $19.8-26.2$ & 0.297 & $0.223-0.371$ & 0.661 & $<0.001$ \\
\hline DMI & \multirow{4}{*}{ PGLS } & 0.038 & $0.021-0.069$ & 0.723 & $0.640-0.806$ & 0.896 & $<0.001$ \\
\hline aDDM & & 67.3 & $49.7-91.2$ & 0.007 & $-0.036-0.050$ & 0.003 & 0.896 \\
\hline DMC & & 0.029 & $0.011-0.074$ & 0.840 & $0.707-0.973$ & 0.819 & $<0.001$ \\
\hline MRT & & 27.4 & 11.4-65.9 & 0.119 & $-0.005-0.243$ & 0.095 & 0.040 \\
\hline \multicolumn{8}{|c|}{$>10 \mathrm{~kg}(\mathrm{n}=41)$} \\
\hline DMI & \multirow{4}{*}{ OLS } & 0.026 & $0.018-0.037$ & 0.885 & $0.815-0.955$ & 0.944 & $<0.001$ \\
\hline $\mathrm{aDDM}$ & & 64.863 & $53.6-78.5$ & -0.029 & $-0.066-0.009$ & 0.058 & 0.129 \\
\hline DMC & & 0.030 & $0.021-0.043$ & 0.924 & $0.854-0.993$ & 0.948 & $<0.001$ \\
\hline MRT & & 41.687 & 29.9-58.2 & 0.026 & $-0.038-0.091$ & 0.017 & 0.414 \\
\hline DMI & \multirow{4}{*}{ PGLS } & 0.029 & $0.010-0.081$ & 0.844 & $0.743-0.945$ & 0.873 & $<0.001$ \\
\hline aDDM & & 54.8 & $34.6-86.7$ & -0.003 & $-0.049-0.042$ & 0.001 & 0.979 \\
\hline DMC & & 0.023 & $0.007-0.070$ & 0.959 & $0.848-1.070$ & 0.880 & $<0.001$ \\
\hline MRT & & 26.3 & $12.1-57.5$ & 0.114 & $0.037-0.190$ & 0.176 & 0.001 \\
\hline
\end{tabular}

882 dry matter intake (DMI in $\mathrm{kg} \mathrm{d}^{-1}$ ); apparent digestibility of dry matter (aDDM in \%); dry 883 matter gut contents (DMC in $\mathrm{kg}$ ); particle mean retention time (MRT in h) 
885 Table 6. Scaling relationships of parameters of digestive physiology with body mass (BM) in 886 the dataset of this study in subsets according to digestion types using OLS and PGLS statistics 887 according to $\mathrm{y}=\mathrm{a} \mathrm{BM}$.

\begin{tabular}{|c|c|c|c|c|c|c|c|}
\hline $\mathbf{y}$ & stats & $\mathbf{a}$ & $95 \% \mathrm{CI}$ & b & $95 \% \mathrm{CI}$ & $\mathbf{r}^{2}$ & p \\
\hline \multicolumn{8}{|c|}{ Caecum fermenter $(n=25)$} \\
\hline DMI & \multirow{4}{*}{ OLS } & 0.041 & $0.036-0.048$ & 0.589 & $0.524-0.654$ & 0.938 & $<0.001$ \\
\hline $\mathrm{aDDM}$ & & 65.3 & $61.4-69.5$ & 0.001 & $-0.029-0.031$ & 0.000 & 0.950 \\
\hline DMC & & 0.025 & $0.021-0.031$ & 0.860 & $0.767-0.954$ & 0.940 & $<0.001$ \\
\hline MRT & & 21.7 & $17.8-26.5$ & 0.271 & $0.177-0.365$ & 0.606 & $<0.001$ \\
\hline DMI & \multirow{4}{*}{ PGLS } & 0.033 & $0.017-0.066$ & 0.688 & $0.594-0.782$ & 0.900 & $<0.001$ \\
\hline $\mathrm{aDDM}$ & & 67.2 & $50.7-89.2$ & -0.003 & $-0.042-0.036$ & 0.001 & 0.977 \\
\hline DMC & & 0.025 & $0.009-0.070$ & 0.830 & $0.689-0.972$ & 0.852 & $<0.001$ \\
\hline MRT & & 27.4 & $11.5-65.1$ & 0.140 & $0.021-0.258$ & 0.187 & 0.013 \\
\hline \multicolumn{8}{|c|}{ Colon fermenter $(\mathrm{n}=15)$} \\
\hline DMI & \multirow{4}{*}{ OLS } & 0.024 & $0.018-0.033$ & 0.911 & $0.856-0.967$ & 0.990 & $<0.001$ \\
\hline $\mathrm{aDDM}$ & & 78.7 & $61.9-100.0$ & -0.066 & $-0.109--0.023$ & 0.459 & 0.006 \\
\hline DMC & & 0.029 & $0.021-0.040$ & 0.919 & $0.861-0.977$ & 0.989 & $<0.001$ \\
\hline MRT & & 47.1 & $27.2-81.5$ & -0.021 & $-0.120-0.077$ & 0.017 & 0.647 \\
\hline DMI & \multirow{4}{*}{ PGLS } & 0.031 & $0.016-0.058$ & 0.852 & $0.757-0.947$ & 0.960 & $<0.001$ \\
\hline $\mathrm{aDDM}$ & & 75.7 & $49.3-116.1$ & -0.070 & $-0.134--0.006$ & 0.259 & 0.032 \\
\hline DMC & & 0.027 & $0.015-0.049$ & 0.948 & $0.858-1.037$ & 0.971 & $<0.001$ \\
\hline MRT & & 34.4 & $14.3-82.6$ & 0.061 & $-0.071-0.192$ & 0.060 & 0.461 \\
\hline \multicolumn{8}{|c|}{ Nonruminant foregut fermenter $(\mathrm{n}=15)$} \\
\hline DMI & \multirow{4}{*}{ OLS } & 0.036 & $0.026-0.051$ & 0.755 & $0.655-0.855$ & 0.953 & $<0.001$ \\
\hline $\mathrm{aDDM}$ & & 69.8 & $56.0-87.3$ & -0.038 & $-0.105-0.030$ & 0.102 & 0.246 \\
\hline DMC & & 0.030 & $0.023-0.038$ & 0.881 & $0.806-0.957$ & 0.980 & $<0.001$ \\
\hline MRT & & 30.3 & $21.4-43.0$ & 0.109 & $0.003-0.215$ & 0.274 & 0.045 \\
\hline DMI & \multirow{4}{*}{ PGLS } & 0.031 & $0.009-0.113$ & 0.812 & $0.659-0.965$ & 0.893 & $<0.001$ \\
\hline $\mathrm{aDDM}$ & & 75.1 & $46.7-120.9$ & -0.064 & $-0.120--0.008$ & 0.276 & 0.025 \\
\hline DMC & & 0.033 & $0.009-0.114$ & 0.844 & $0.697-0.992$ & 0.907 & $<0.001$ \\
\hline MRT & & 40.2 & $11.1-145.1$ & 0.006 & $-0.145-0.158$ & 0.001 & 0.993 \\
\hline \multicolumn{8}{|c|}{ Ruminant $(n=22)$} \\
\hline DMI & \multirow{4}{*}{ OLS } & 0.054 & $0.035-0.083$ & 0.752 & $0.659-0.845$ & 0.934 & $<0.001$ \\
\hline $\mathrm{aDDM}$ & & 66.7 & $51.6-86.3$ & -0.025 & $-0.080-0.030$ & 0.044 & 0.347 \\
\hline DMC & & 0.041 & $0.024-0.067$ & 0.897 & $0.788-1.005$ & 0.937 & $<0.001$ \\
\hline MRT & & 27.6 & $20.2-37.7$ & 0.133 & $0.066-0.200$ & 0.464 & $<0.001$ \\
\hline DMI & \multirow{4}{*}{ PGLS } & 0.036 & $0.014-0.093$ & 0.765 & $0.660-0.870$ & 0.910 & $<0.001$ \\
\hline $\mathrm{aDDM}$ & & 85.3 & $42.8-169.9$ & -0.072 & $-0.149-0.005$ & 0.144 & 0.055 \\
\hline DMC & & 0.024 & $0.007-0.078$ & 0.973 & $0.841-1.104$ & 0.913 & $<0.001$ \\
\hline MRT & & 26.3 & $13.2-52.5$ & 0.177 & $0.100-0.254$ & 0.502 & $<0.001$ \\
\hline
\end{tabular}

888 dry matter intake (DMI in $\mathrm{kg} \mathrm{d}^{-1}$ ); apparent digestibility of dry matter (aDDM in \%); dry 889 matter gut contents (DMC in kg); particle mean retention time (MRT in h) 
893 Table 7. Correlations between body mass residuals of parameters of digestive physiology in 894 the dataset of this study $(\mathrm{n}=77)$ analysed by OLS and PGLS statistics (differences indicated 895 by grey shading).

\begin{tabular}{lllll}
\hline & Stats & Residual aD DM & Residual DMC & Residual MRT \\
\hline Residual DMI & OLS & $\mathrm{R}=-0.254, \mathrm{p}=0.026$ & $\mathrm{R}=0.444, \mathrm{p}<0.001$ & $\mathrm{R}=-0.583, \mathrm{p}<0.001$ \\
& PGLS & $\mathrm{R}=0.087, \mathrm{p}=0.567$ & $\mathrm{R}=0.589, \mathrm{p}<0.001$ & $\mathrm{R}=-0.270, \mathrm{p}=0.004$ \\
Residual aD DM & OLS & & $\mathrm{R}=-0.082, \mathrm{p}=0.471$ & $\mathrm{R}=0.345, \mathrm{p}=0.002$ \\
& PGLS & & $\mathrm{R}=-0.200, \mathrm{p}=0.050$ & $\mathrm{R}=-0.084, \mathrm{p}=0.592$ \\
Residual DMC & OLS & & & $\mathrm{R}=0.450, \mathrm{p}<0.001$ \\
& PGLS & & & $\mathrm{R}=0.593, \mathrm{p}<0.001$ \\
\hline
\end{tabular}

896 dry matter intake (DMI in $\mathrm{kg} \mathrm{d}^{-1}$ ); apparent digestibility of dry matter (aDDM in \%); dry 897 matter gut contents (DMC in kg); particle mean retention time (MRT in h) 

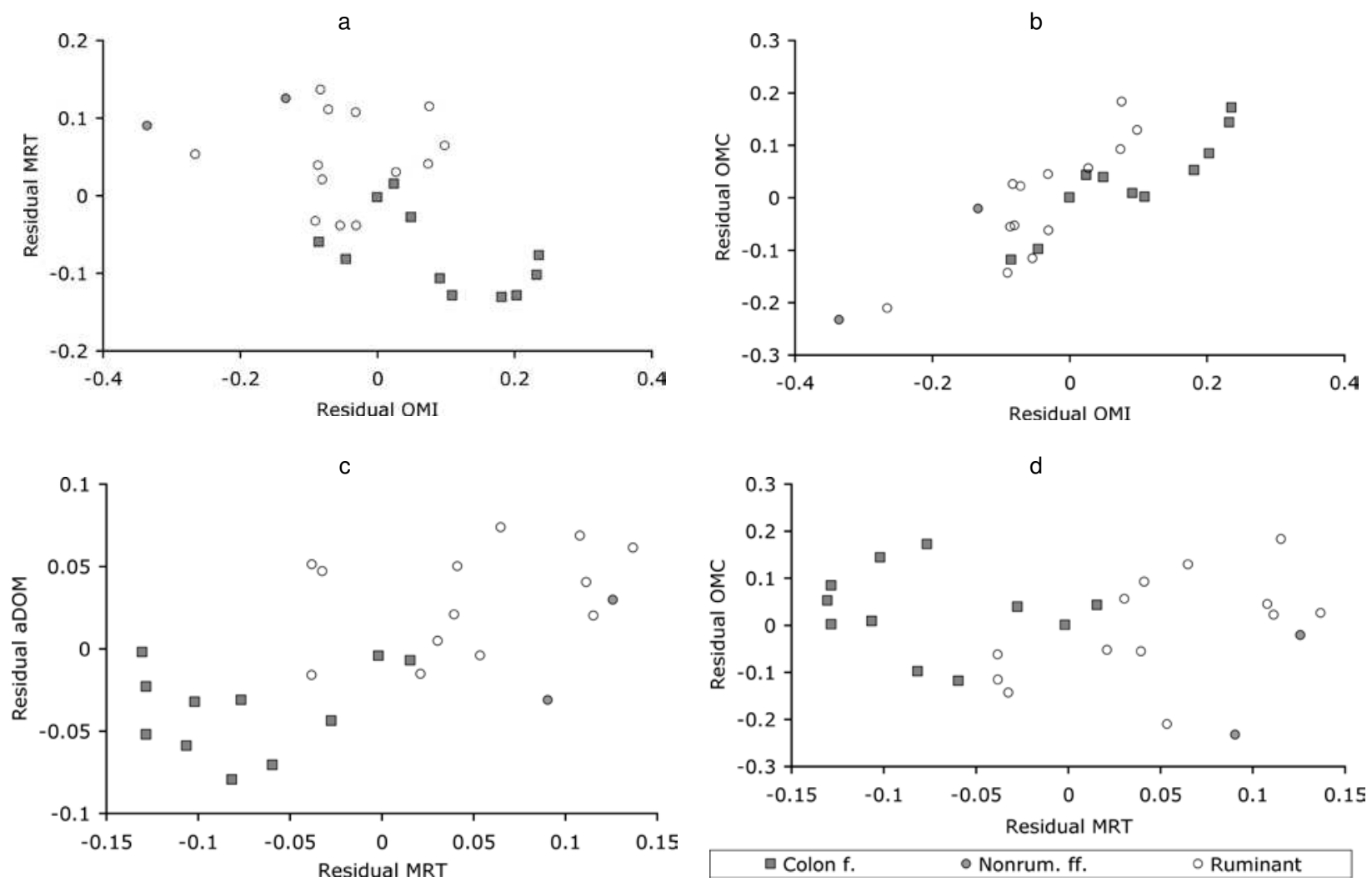

899 Fig. 1. Relationships between body mass residuals of different parameters of digestive

900 physiology (organic matter intake OMI in $\mathrm{kg} \mathrm{d}^{-1}$; particle mean retention time MRT in h;

901 organic matter gut contents OMC in $\mathrm{kg}$, apparent organic matter digestibility aDOM in \%) in

902 large mammalian herbivores of different digestion types (colon fermenters, nonruminant

903 foregut fermenters, ruminants) in the dataset of Foose (1982). a) OMI and MRT; b) OMI and

904 OMC; c) MRT and aDOM; d) MRT and OMC. For statistics, see Table 2. 

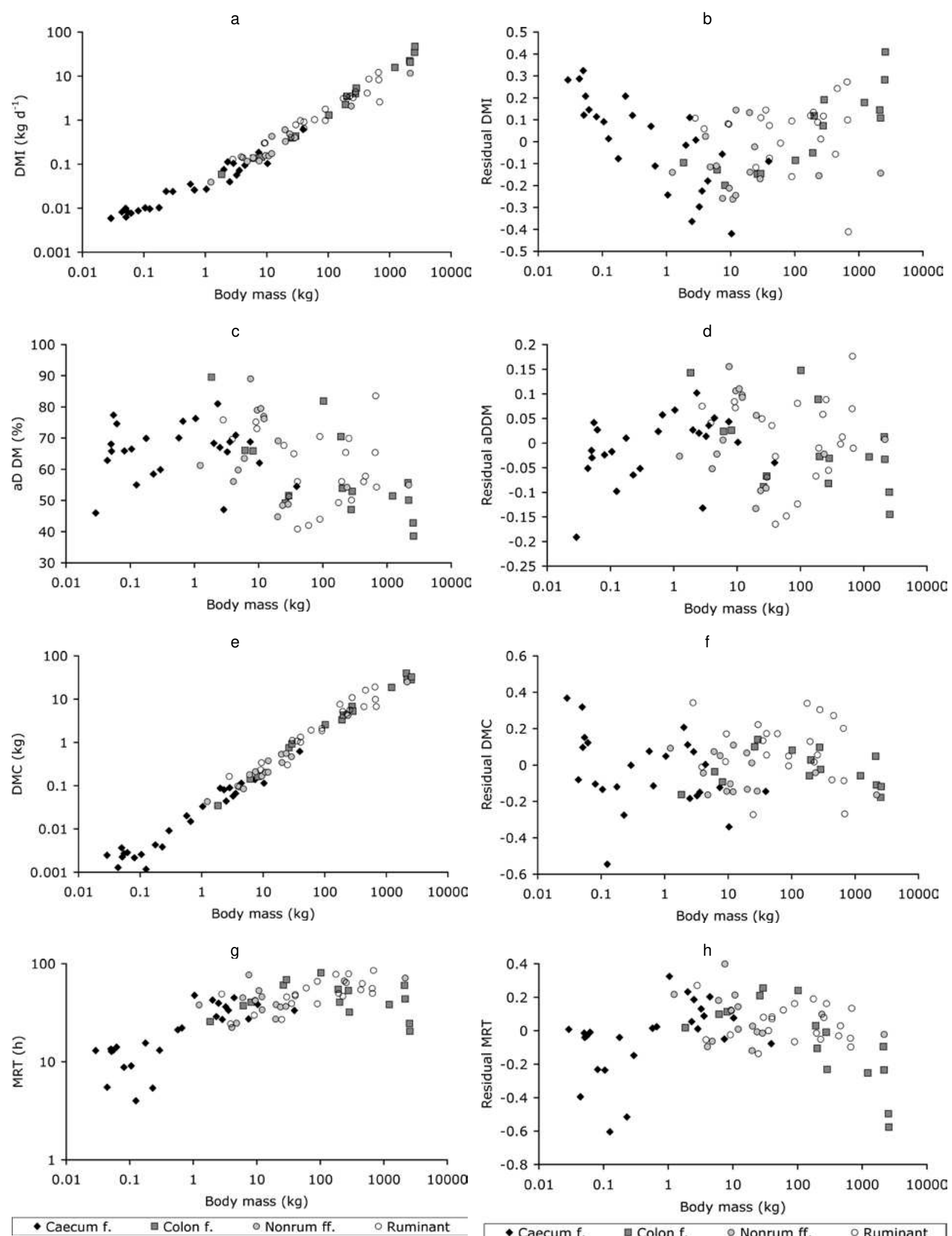

Figure 2. Scaling relationships between body mass (BM) and parameters of digestive physiology (left side) and plots of body mass-residuals of these parameters against body mass to visualize patterns of quadratic scaling (curvatures) (right side) in mammalian herbivores of different digestion types (caecum fermenters, colon fermenters, nonruminant foregut fermenters, ruminants). a,b) dry matter intake (DMI); c,d) apparent digestibility of dry matter ( $\mathrm{aD} \mathrm{DM})$; e,f) dry matter gut contents (DMC); g,h) particle mean retention time (MRT). For statistics, see Tables 3-6. 

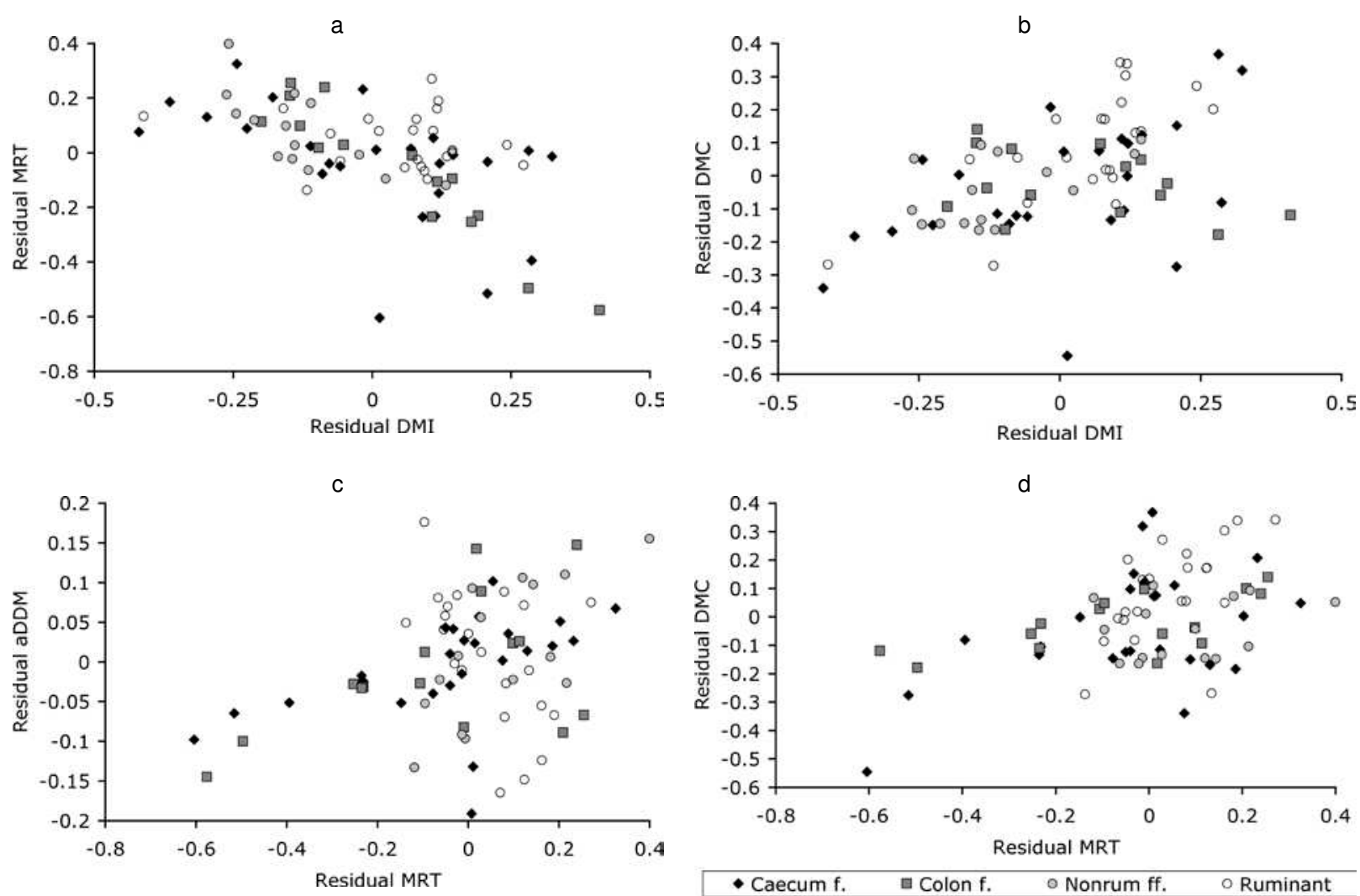

916 Fig. 3. Relationships between body mass residuals of different parameters of digestive physiology (dry matter intake DMI in $\mathrm{kg} \mathrm{d}^{-1}$; particle mean retention time MRT in h; dry matter gut contents DMC in kg, apparent dry matter digestibility aDDM in \%) in mammalian herbivores of different digestion types (colon fermenters, nonruminant foregut fermenters, ruminants) in the dataset of this study. a) DMI and MRT; b) DMI and DMC; c) MRT and aDDM; d) MRT and DMC. For statistics, see Table 7. 


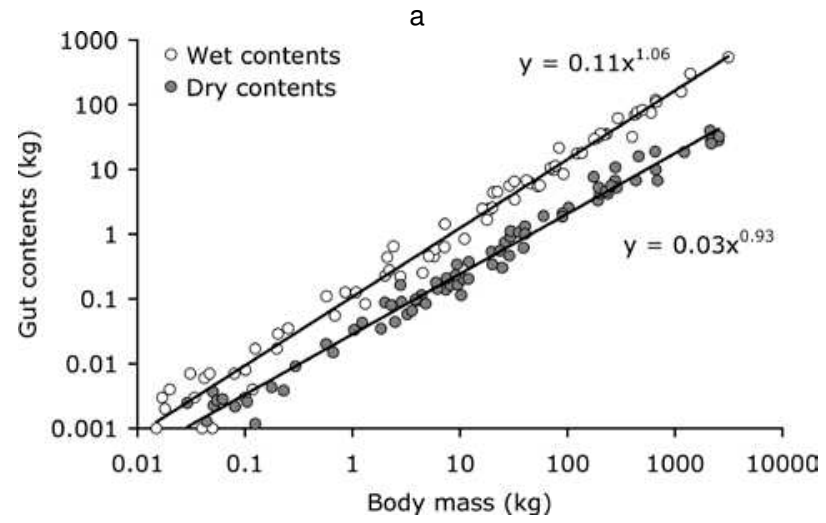

924 Figure 4. Scaling of wet gut contents (open symbols, Clauss et al., 2007a) and dry matter gut 925 contents (closed symbols, this study) with body mass. Note the increasing difference between 926 the two with increasing body mass. 
Assessing the Jarman-Bell-principle: scaling of intake, digestibility, retention time and gut capacity with body mass in mammalian herbivores

Dennis W.H. Müller ${ }^{1,2}$, Daryl Codron ${ }^{1,3}$, Carlo Meloro ${ }^{4}$, Adam Munn ${ }^{5}$, Angela Schwarm ${ }^{6}$, Jürgen Hummel ${ }^{7}$, Marcus Clauss ${ }^{1 *}$

${ }^{1}$ Clinic for Zoo Animals, Exotic Pets and Wildlife, Vetsuisse Faculty, University of Zurich, Winterthurerstr. 260, 8057 Zurich, Switzerland,, mclauss@ @etclinics.uzh.ch

${ }^{2}$ National Park 'Bavarian Forest', Freyungerstr. 2, 94481 Grafenau, Germany

${ }^{3}$ Florisbad Quaternary Research, National Museum, Bloemfontein, 9300, RSA

${ }^{4}$ Center for Anatomical and Human Science, Hull York Medical School, University of Hull, Cottingham Road, Hull HU6 3RX, UK

${ }^{5}$ Institute for Conservation Biology and Environmental Management, School of Biological Sciences, The University of Wollongong, New South Wales 2522 Australia

${ }^{6}$ Research Unit Nutritional Physiology 'Oskar Kellner', Leibniz Institute for Farm Animal Biology (FBN), Wilhelm-Stahl-Allee 2, 18196 Dummerstorf, Germany

${ }^{7}$ Institute of Animal Science, University of Bonn, Endenicher Allee 15, 53115 Bonn, Germany

\section{Supplements}


Table 1. Dataset from Foose (1982)

Gastrointestinal anatomy (GIT-Anatomy), mean of body mass (BM), organic matter intake (OMI), mean retention time of particle markers (different markers) through the whole gastrointestinal tract (MRT), apparent digestibility of organic matter (aD OM) and calculated mass of organic matter gastrointestinal tract content (OMC) of 26 herbivorous

\begin{tabular}{|c|c|c|c|c|c|c|}
\hline Species & GIT-Anatomy & BM (kg) & OM $(\mathrm{kg} / \mathrm{d})$ & MRT (h) & $\operatorname{aD~OM}(\%)$ & OMC $(\mathrm{kg})$ \\
\hline Tapirus terrestris & 2 & 140 & 2.239 & 46 & 49.0 & 3.24 \\
\hline Equus asinus & 2 & 183 & 5.747 & 45 & 53.8 & 7.86 \\
\hline Boselaphus tragocamelus & 4 & 193 & 2.848 & 59 & 60.8 & 4.87 \\
\hline Cervus duvaucelii & 4 & 193 & 2.822 & 50 & 64.5 & 3.98 \\
\hline Hexaprotodon liberiensis & 3 & 200 & 1.649 & 67 & 53.9 & 3.34 \\
\hline Oryx gazella & 4 & 204 & 4.318 & 71 & 60.7 & 8.84 \\
\hline Kobus ellipsiprymnus & 4 & 204 & 3.859 & 58 & 58.6 & 6.59 \\
\hline Tapirus indicus & 2 & 218 & 3.432 & 45 & 48.3 & 4.88 \\
\hline Equus zebra & 2 & 265 & 7.553 & 44 & 54.0 & 9.98 \\
\hline Equus burchellii & 2 & 272 & 7.200 & 41 & 55.2 & 8.91 \\
\hline Cervus elaphus & 4 & 284 & 3.874 & 58 & 56.2 & 6.73 \\
\hline Syncerus caffer & 4 & 291 & 5.954 & 64 & 69.0 & 10.44 \\
\hline Equus grevyi & 2 & 353 & 8.347 & 42 & 58.1 & 10.24 \\
\hline Taurotragus oryx & 4 & 431 & 5.959 & 52 & 56.5 & 9.27 \\
\hline Bison bison & 4 & 499 & 6.651 & 74 & 68.8 & 13.36 \\
\hline Camelus bactrianus & 4 & 544 & 6.308 & 79 & 67.7 & 13.73 \\
\hline Camelus dromedarius & 4 & 544 & 6.477 & 75 & 64.5 & 13.62 \\
\hline Bos frontalis & 4 & 765 & 8.728 & 54 & 66.5 & 13.11 \\
\hline Giraffa camelopardalis & 4 & 1153 & 7.321 & 69 & 58.9 & 14.74 \\
\hline Bubalus bubalis & 4 & 1270 & 17.232 & 67 & 66.8 & 32.03 \\
\hline Diceros bicornis & 2 & 1285 & 16.419 & 57 & 53.8 & 28.62 \\
\hline Ceratotherium simum & 2 & 1752 & 18.550 & 62 & 59.2 & 33.73 \\
\hline Rhinoceros unicornis & 2 & 1852 & 20.468 & 65 & 58.9 & 38.96 \\
\hline Hippopotamus amphibius & 3 & 2240 & 16.443 & 85 & 64.3 & 39.28 \\
\hline Loxodonta africana & 2 & 2873 & 34.729 & 48 & 53.4 & 50.72 \\
\hline Elephas maximus & 2 & 3034 & 34.748 & 51 & 52.6 & 53.86 \\
\hline
\end{tabular}

GIT-Anatomy = gastrointestinal tract anatomy: $2=$ colon fermenter, $3=$ nonruminant foregut fermenter, $4=$ ruminant foregut fermenter 
Table 2. Data collection of this study

Gastrointestinal anatomy (GIT-Anatomy), number of offspring per litter (Nos offspring) mean of body mass (BM), dry matter intake (DMI), mean retention time of particle markers (different markers) through the whole gastrointestinal tract (MRT), apparent digestibility of dry matter (aD DM) and calculated mass of dry matter gastrointestinal tract content (DMC) of 77 herbivorous mammalian species for which all relevant data were measured in individual studies

\begin{tabular}{|c|c|c|c|c|c|c|c|c|}
\hline Species & $\begin{array}{c}\text { GIT- } \\
\text { Anatomy }\end{array}$ & $\begin{array}{c}\text { Nos } \\
\text { offspring }\end{array}$ & $\begin{array}{l}\text { BM } \\
(\mathrm{kg})\end{array}$ & $\begin{array}{c}\text { DMI } \\
(\mathrm{kg} / \mathrm{d})\end{array}$ & $\begin{array}{c}\text { MRT } \\
\text { (h) }\end{array}$ & $\begin{array}{c}\text { aD } \\
\text { DM } \\
(\%)\end{array}$ & $\begin{array}{c}\text { DMC } \\
(\mathrm{kg})\end{array}$ & Source \\
\hline Mus musculus & 1 & $>1$ & 0.03 & 0.006 & 13.0 & 46.0 & 0.002 & (Karasov et al., 1986) \\
\hline Meriones unguiculatus & 1 & $>1$ & 0.05 & 0.006 & 12.8 & 65.8 & 0.002 & (Pei et al., 2001b) \\
\hline Microtus ochrogaster & 1 & $>1$ & 0.05 & 0.010 & 13.5 & 68.1 & 0.004 & (Hammond and Wunder, 1991) \\
\hline Microtus townsendii & 1 & $>1$ & 0.05 & 0.008 & 13.1 & 77.4 & 0.003 & (Hume et al., 1993) \\
\hline Phyllotis darwini & 1 & $>1$ & 0.08 & 0.009 & 8.8 & 65.9 & 0.002 & (Sakaguchi and Ohmura, 1992) \\
\hline Cricetus cricetus & 1 & $>1$ & 0.11 & 0.011 & 9.1 & 66.5 & 0.003 & (Sakaguchi et al., 1987) \\
\hline Neotoma lepida & 1 & $>1$ & 0.13 & 0.010 & 4.0 & 55.0 & 0.001 & (Karasov et al., 1986) \\
\hline Octodon degus & 1 & $>1$ & 0.18 & 0.010 & 15.5 & 69.9 & 0.004 & (Sakaguchi and Ohmura, 1992) \\
\hline Arvicola terrestris & 1 & $>1$ & 0.23 & 0.024 & 5.4 & 58.5 & 0.004 & (Woodall, 1989) \\
\hline Rattus norvegicus & 1 & $>1$ & 0.30 & 0.024 & 13.1 & 59.9 & 0.009 & (Sakaguchi et al., 1987) \\
\hline Cavia porcellus & 1 & $>1$ & 0.57 & 0.036 & 21.1 & 70.1 & 0.020 & $\begin{array}{l}\text { (Sakaguchi et al., 1987; Sakaguchi and Nabata, 1992; Sakaguchi et al., 1992b; Sakaguchi and Ohmura, 1992; } \\
\text { Franz et al., 2011) }\end{array}$ \\
\hline Hapalemur griseus & 1 & 1 & 1.04 & 0.027 & 47.5 & 76.3 & 0.033 & (Campbell et al., 2004) \\
\hline Oryctolagus cuniculus & 1 & $>1$ & 2.01 & 0.079 & 42.6 & 68.4 & 0.088 & (Sakaguchi et al., 1987; Sakaguchi and Hume, 1990; Sakaguchi et al., 1992a; Franz et al., 2011) \\
\hline Marmota caligata & 1 & $>1$ & 2.31 & 0.112 & 28.9 & 81.0 & 0.080 & (Hume et al., 1993) \\
\hline Trichosurus vulpecula & 1 & 1 & 2.50 & 0.040 & 39.6 & 67.0 & 0.044 & (Sakaguchi and Hume, 1990) \\
\hline Lagostomus maximus & 1 & $>1$ & 2.86 & 0.105 & 27.0 & 47.0 & 0.090 & (Besselmann, 2005; Clauss et al., 2007a) \\
\hline Propithecus tattersalli & 1 & 1 & 3.24 & 0.057 & 36.3 & 65.6 & 0.058 & (Campbell et al., 1999) \\
\hline Propithecus verreauxi & 1 & 1 & 3.58 & 0.072 & 33.5 & 68.8 & 0.066 & (Campbell et al., 1999; Campbell et al., 2004) \\
\hline Myocastor coypus & 1 & $>1$ & 4.40 & 0.094 & 45.0 & 70.9 & 0.114 & (Sakaguchi and Nabata, 1992) \\
\hline Dolichotis patagonum & 1 & $>1$ & 7.40 & 0.185 & 27.3 & 68.8 & 0.138 & (Sakaguchi et al., 1992b) \\
\hline Erethizon dorsatum & 1 & 1 & 10.3 & 0.103 & 38.4 & 62.0 & 0.114 & (Felicetti et al., 2000) \\
\hline Hydrochaeris hydrochaeris & 1 & $>1$ & 39.2 & 0.606 & 33.3 & 54.5 & 0.620 & (A. Schwarm, S. Ortmann, M. Clauss pers. obs. 2010) \\
\hline
\end{tabular}




\begin{tabular}{|c|c|c|c|c|c|c|c|c|}
\hline Pithecia pithecia & 2 & 1 & 1.85 & 0.059 & 25.6 & 89.5 & 0.035 & (Norconk et al., 2002) \\
\hline Alouatta pigra & 2 & 1 & 6.15 & 0.137 & 37.3 & 66.1 & 0.142 & (Edwards and Ullrey, 1999) \\
\hline Alouatta seniculus & 2 & 1 & 8.18 & 0.144 & 40.4 & 65.9 & 0.163 & (Edwards and Ullrey, 1999) \\
\hline Lasiorhinus latifrons & 2 & 1 & 26.2 & 0.394 & 60.5 & 49.2 & 0.750 & (Barboza, 1993) \\
\hline Vombatus ursinus & 2 & 1 & 29.5 & 0.434 & 68.5 & 51.6 & 0.918 & (Barboza, 1993) \\
\hline Gorilla gorilla & 2 & 1 & 102 & 1.267 & 80.6 & 81.9 & 2.560 & (Remis and Dierenfeld, 2004) \\
\hline Tapirus terrestris & 2 & 1 & 192 & 2.247 & 54.7 & 70.5 & 3.320 & (Clauss et al., 2010) \\
\hline Equus asinus & 2 & 1 & 202 & 3.445 & 40.5 & 53.9 & 4.250 & (Pearson and Merritt, 1991; Pearson et al., 2001, 2006) \\
\hline Tapirus indicus & 2 & 1 & 278 & 3.945 & 53.1 & 47.1 & 6.720 & (Clauss et al., 2010) \\
\hline Equus caballus & 2 & 1 & 287 & 5.416 & 32.0 & 52.9 & 5.250 & $\begin{array}{l}\text { (Pearson and Merritt, 1991; Pagan et al., 1998; Pearson et al., 2001; Moore-Colyer et al., 2003; Pearson et al., } \\
\text { 2006) }\end{array}$ \\
\hline Diceros bicornis & 2 & 1 & 1222 & 15.700 & 38.3 & 51.4 & 18.614 & (Clauss et al., 2005a; Clauss et al., 2006; Steuer et al., 2010) \\
\hline Rhinoceros unicornis & 2 & 1 & 2125 & 22.065 & 60.1 & 55.7 & 39.935 & (Clauss et al., 2005b) \\
\hline Ceratotherium simum & 2 & 1 & 2175 & 20.781 & 43.8 & 50.1 & 28.286 & (Steuer et al., 2010) \\
\hline Elephas maximus & 2 & 1 & 2547 & 33.874 & 24.5 & 42.8 & 27.998 & (Hackenberger, 1987) \\
\hline Loxodonta africana & 2 & 1 & 2583 & 47.207 & 20.5 & 38.6 & 32.515 & (Hackenberger, 1987) \\
\hline Lagorchestes hirsutus & 3 & 1 & 1.23 & 0.040 & 38.0 & 61.3 & 0.043 & (Bridie et al., 1994) \\
\hline Thylogale thetis & 3 & 1 & 4.05 & 0.141 & 22.4 & 56.1 & 0.095 & (Dellow, 1982; Dellow and Hume, 1982) \\
\hline Macropus eugenii & 3 & 1 & 4.80 & 0.117 & 24.8 & 59.8 & 0.084 & (Dellow, 1982; Dellow and Hume, 1982) \\
\hline Trachypithecus auratus & 3 & 1 & 6.00 & 0.140 & 45.0 & 63.5 & 0.179 & (Nijboer et al., 2007) \\
\hline Colobus angolensis & 3 & 1 & 7.50 & 0.118 & 77.0 & 89.0 & 0.210 & (Schwarm et al., 2009a) \\
\hline Trachypithecus johnii & 3 & 1 & 9.50 & 0.157 & 42.0 & 79.0 & 0.166 & (Comizzoli et al., 1997; Schwarm et al., 2009a) \\
\hline Colobus guereza & 3 & 1 & 10.8 & 0.154 & 53.1 & 79.5 & 0.206 & (Edwards and Ullrey, 1999) \\
\hline Colobus polykomos & 3 & 1 & 12 & 0.174 & 46.0 & 77.0 & 0.205 & (Schwarm et al., 2009a) \\
\hline Pygathrix nemaeus & 3 & 1 & 12.1 & 0.429 & 33.8 & 76.2 & 0.374 & (Edwards and Ullrey, 1999) \\
\hline Macropus robustus & 3 & 1 & 19.8 & 0.608 & 27.2 & 44.7 & 0.534 & (Freudenberger and Hume, 1992) \\
\hline Pecari tajacu & 3 & $>1$ & 20.1 & 0.324 & 38.2 & 69.1 & 0.343 & (Schwarm et al., 2009a) \\
\hline Macropus giganteus & 3 & 1 & 23.6 & 0.504 & 36.2 & 48.4 & 0.555 & (Forbes and Tribe, 1970; Dellow, 1982; Dellow and Hume, 1982) \\
\hline Macropus rufus & 3 & 1 & 28.7 & 0.468 & 36.7 & 48.8 & 0.467 & $\begin{array}{l}\text { (Foot and Romberg, 1965; McIntosh, 1966; Forbes and Tribe, 1970; Dellow, 1982; Dellow and Hume, 1982; } \\
\text { Munn and Dawson, 2006; Schwarm et al., 2009a) }\end{array}$ \\
\hline Hexaprotodon liberiensis & 3 & 1 & 238 & 2.067 & 66.5 & 54.3 & 4.215 & (Clauss et al., 2004) \\
\hline Hippopotamus amphibius & 3 & 1 & 2175 & 11.733 & 71.4 & 55.0 & 25.011 & (Clauss et al., 2004) \\
\hline Tragulus napu & 4 & 1 & 2.8 & 0.129 & 49.0 & 75.8 & 0.164 & (Conklin and Dierenfeld, 1994) \\
\hline
\end{tabular}




\begin{tabular}{|c|c|c|c|c|c|c|c|c|}
\hline Cephalophus monticola & 4 & 1 & 3.85 & 0.146 & 24.4 & 69.6 & 0.098 & (Luginbuhl et al., 1990) \\
\hline Pudu puda & 4 & 1 & 9.1 & 0.299 & 29.9 & 75.2 & 0.232 & (Conklin-Brittain and Dierenfeld, 1996) \\
\hline Cephalophus maxwellii & 4 & 1 & 9.4 & 0.305 & 42.2 & 73.0 & 0.341 & (Conklin-Brittain and Dierenfeld, 1996) \\
\hline Capreolus capreolus & 4 & $>1$ & 24.7 & 0.405 & 27.0 & 67.7 & 0.302 & (Holand, 1994) \\
\hline Capra hircus & 4 & 1 & 29.7 & 0.777 & 45.9 & 51.3 & 1.117 & (Udén et al., 1982; Udén and Van Soest, 1982; Freudenberger and Hume, 1992; Kennedy et al., 1992) \\
\hline Capra ibex & 4 & 1 & 35.4 & 0.989 & 39.3 & 65.0 & 1.074 & (Gross et al., 1996) \\
\hline Odocoileus virginianus & 4 & $>1$ & 40.3 & 0.648 & 47.0 & 40.9 & 1.011 & (Barnes et al., 1992) \\
\hline Ovis ammon & 4 & 1 & 40.3 & 0.914 & 48.4 & 56.1 & 1.325 & $\begin{array}{l}\text { (Foot and Romberg, 1965; McIntosh, 1966; Forbes and Tribe, 1970; Dellow, 1982; Dellow and Hume, 1982; } \\
\text { Udén et al., 1982; Udén and Van Soest, 1982; Luginbuhl et al., 1990; Kennedy et al., 1992; Pearson et al., } \\
\text { 2006) }\end{array}$ \\
\hline Odocoileus hemionus & 4 & $>1$ & 60 & 1.028 & 56.7 & 42.0 & 1.918 & (Baker and Hobbs, 1987) \\
\hline Bubalus depressicornis & 4 & 1 & 90 & 1.767 & 39.0 & 70.5 & 1.858 & (Flores-Miyamoto et al., 2005) \\
\hline Ovis canadensis & 4 & 1 & 90 & 0.984 & 66.0 & 44.0 & 2.111 & (Baker and Hobbs, 1987) \\
\hline Bos grunniens & 4 & 1 & 176 & 3.122 & 78.2 & 49.3 & 7.663 & (Schaefer et al., 1978) \\
\hline Cervus elaphus & 4 & 1 & 196 & 3.763 & 49.7 & 56.1 & 5.226 & (Baker and Hobbs, 1987; Jiang and Hudson, 1996) \\
\hline Okapia johnstoni & 4 & 1 & 227 & 3.531 & 46.8 & 65.4 & 4.626 & (Hummel et al., 2005; Hummel et al., 2006) \\
\hline Ovibos moschatus & 4 & 1 & 254 & 3.223 & 64.2 & 69.9 & 5.623 & (Adamczewski et al., 1993; Barboza et al., 2006) \\
\hline Bos javanicus & 4 & 1 & 432 & 4.654 & 54.2 & 56.0 & 6.711 & (Schwarm et al., 2008, 2009b) \\
\hline Bos taurus & 4 & 1 & 460 & 7.357 & 62.8 & 57.8 & 16.052 & $\begin{array}{l}\text { (Schaefer et al., 1978; Colucci et al., 1982; Udén et al., 1982; Udén and Van Soest, 1982; Mathers et al., 1989; } \\
\text { Luginbuhl et al., 1994; Burns et al., 1997; Whetsell et al., 2004; Pearson et al., 2006) }\end{array}$ \\
\hline Bubalus bubalis & 4 & 1 & 656 & 12.120 & 56.0 & 65.4 & 19.037 & (Mathers et al., 1989) \\
\hline Giraffa camelopardalis & 4 & 1 & 665 & 8.224 & 49.8 & 83.5 & 9.942 & (Schaub, 2005) \\
\hline Camelus bactrianus & 4 & 1 & 687 & 2.601 & 85.2 & 54.3 & 6.724 & (Cahill and McBride, 1995) \\
\hline
\end{tabular}

GIT-Anatomy = gastrointestinal tract anatomy: $1=$ caecum fermenter, $2=$ colon fermenter, $3=$ nonruminant foregut fermenter, $4=$ ruminant foregut fermenter; BM = body mass;

$\mathrm{DMI}=$ dry matter intake; MRT = mean retention time of particle markers (different markers) through the whole gastrointestinal tract; aD DM = apparent dry matter digestibility;

$\mathrm{DMC}=$ mass of dry matter gastrointestinal tract content calculated according to Holleman and White (1989; for equations see the main text)

Table 3. Data collection of wet gut contents

This dataset is given as the supplement to Clauss et al. (2007b). 


\section{References}

Adamczewski, J.Z., Chapin, R.E., Schaefer, J.A., Flood, P.F., 1993. Intake, digestibility and passage rate of a supplemented hay diet in captive muskoxen. Rangifer 13, 57-60. Baker, D.L., Hobbs, N.T., 1987. Strategies of digestion: digestive efficiency and retention times of forage diets in montane ungulates. Can. J. Zool. 65, $1978-1984$.

Barboza, P.S., 1993. Digestive strategies of the wombats: feed intake, fiber digestion, and digesta passage in two grazing marsupials with hindgut fermentation. Physiol. Zool. 66, 983-999.

Barboza, P.S., Peltier, T.C., Forster, R.J., 2006. Ruminal fermentation and fill change with season in an Arctic grazer: responses to hyperphagia and hypophagia in muskoxen (Ovibos moschatus). Physiol. Biochem. Zool. 79, 497-513.

Barnes, T.G., Varner, L.W., blankenship, L.H., Gallagher, J.F., 1992. Indigestible particulate passage in white-tailed deer, in: R. Brown (Ed.), The biology of deer. Springer Verlag, New York, 436442

Besselmann, D., 2005. Untersuchungen zur Anatomie und Verdauungsphysiologie des Flachland-Viscachas (Lagostomus maximus). Diss. thesis, University of Zurich.

Bridie, A., Hume, I.D., Hill, D.M., 1994. Digestive tract function and energy requirements of the rufous hare-wallaby (Lagorchestes hirsutus). Aust. J. Zool. 42, 761-774.

Burns, J.C., Pond, K.R., Fisher, D.S., Luginbuhl, J.M., 1997. Changes in forage quality, ingestive mastication, and digesta kinetics resulting from switchgrass maturity. J. Anim. Sci. 75, 1368-1379.

Cahill, L.W., McBride, B.W., 1995. Effect of level of intake on digestion, rate of passage and chewing dynamics in hay-fed Bactrian camels. Proceedings of the Nutrition Advisory Group 1, 3-35.

Campbell, J.L., Eisemann, J.H., Glander, K.E., Crissey, S.D., 1999. Intake, digestibility, and passage of a commercially designed diet by two propithecus species. Am. J. Primatol. 48, 237-246.

Campbell, J.L., Williams, C.V., Eisemann, J.H., 2004. Use of total dietary fiber across four lemur species (Propithecus cerreauxi coquereli, Hapalemur griseus griseus, Varecia variegata, and

Eulemur fulvus): does fiber type affect digestive efficiency? Am. J. Primatol. 64, 323-335.

Clauss, M., Schwarm, A., Ortmann, S., Alber, D., Flach, E.J., Kühne, R., Hummel, J., Streich, W.J., Hofer, H., 2004. Intake, ingesta retention, particle size distribution and digestibility in the hippopotamidae. Comp. Biochem. Physiol. A 139, 449-459.

Clauss, M., Froeschle, T., Castell, J., Hummel, J., Hatt, J.M., Ortmann, S., Streich, W.J., 2005a. Fluid and particle retention times in the black rhinoceros (Diceros bicornis), a large hindgutfermenting browser. Acta Theriol. 50, 367-376.

Clauss, M., Polster, C., Kienzle, E., Wiesner, H., Baumgartner, K., von Houwald, F., Ortmann, S., Streich, W.J., Dierenfeld, E.S., 2005b. Studies on digestive physiology and feed digestibilities in captive Indian rhinoceros (Rhinoceros unicornis). J. Anim. Physiol. Anim. Nutr. 89, 229-237.

Clauss, M., Castell, J.C., Kienzle, E., Dierenfeld, E.S., Flach, E.J., Behlert, O., Ortmann, S., Streich, W.J., Hummel, J., Hatt, J.M., 2006. Digestion coefficients achieved by the black rhinoceros (Diceros bicornis), a large browsing hindgut fermenter. J. Anim. Physiol. Anim. Nutr. 90, 325-334.

Clauss, M., Besselmann, D., Schwarm, A., Ortmann, S., Hatt, J.M., 2007a. Demonstrating coprophagy with passage markers? The example of the plains viscacha (Lagostomus maximus). Comp. Biochem. Physiol. A 147, 453-459.

Clauss, M., Schwarm, A., Ortmann, S., Streich, W.J., Hummel, J., 2007b. A case of non-scaling in mammalian physiology? Body size, digestive capacity, food intake, and ingesta passage in mammalian herbivores. Comp. Biochem. Physiol. A 148, 249-265.

Clauss, M., Lang-Deuerling, S., Müller, D.W.H., Kienzle, E., Steuer, P., Hummel, J., 2010. Retention of fluid and particles in captive tapirs (Tapirus spp.). Comp. Biochem. Physiol. A 157, 95-101. Colucci, P.E., Chase, L.E., Van Soest, P.J., 1982. Feed intake, apparent diet digestibility, and rate of particulate passage in dairy cattle. J. Dairy Sci. 65, 1445-1456.

Comizzoli, P., Peiniau, J., Dutertre, C., Planquette, P., Aumaitre, A., 1997. Digestive utilization of concentrated and fibrous diets by two peccary species (Tayassu peccari, Tayassu tajacu) raised in French Guyana. Anim. Feed Sci. Technol. 64, 215-226.

Conklin, N.L., Dierenfeld, E.S., 1994. Digestibility and passage of standard zoo diet fed to greater Asian mouse deer (Tragulus naphu). Malayan Nature Journal 48, 41-51

Conklin-Brittain, N.L., Dierenfeld, E.S., 1996. Small ruminants: digestive capacity differences among four species weighing less than $20 \mathrm{~kg}$. Zoo Biol. 15 , $481-490$.

Dellow, D.W., 1982. Studies on the nutrition of macropodine marsupials. III. The flow of digesta through the stomach and intestine of macropodines and sheep. Aust. J. Zool. 30, 399-406.

Dellow, D.W., Hume, I.D., 1982. Studies on the nutrition of macropodine marsupials. I. Intake and digestion of lucerne hay and fresh grass. Aust. J. Zool. 30 , 391-398.

Edwards, M.S., Ullrey, D.E., 1999. Effect of dietary fiber concentration on apparent digestibility and digesta passage in non-human primates. II. Hindgut- and foregut-fermenting folivores. Zoo Biol. $18,537-549$

Felicetti, L.A., Shipley, L.A., Witmer, G.W., Robbins, C.T., 2000. Digestibility, nitrogen excretion, and mean retention time by North American porcupines (Erethizon dorsatum) consuming natural forages. Physiol. Biochem. Zool. 73, 772-780.

Flores-Miyamoto, K., Clauss, M., Ortmann, S., Sainsbury, A.W., 2005. The nutrition of captive lowland anoa (Bubalus depressicornis): a study on ingesta passage, intake, digestibility, and a diet survey. Zoo Biol. 24, 125-134.

Foose, T.J., 1982. Trophic strategies of ruminant versus nonruminant ungulates. University of Chicago, Chicago. 
Foot, J.Z., Romberg, B., 1965. The utilization of roughage by sheep and the red kangaroo (Macropus rufus). Austr. J. Agric. Res. 16, 429-435.

Forbes, D.K., Tribe, D.E., 1970. The utilization of roughages by sheep and kangaroos. Aust. J. Zool. 18, 247-256.

Franz, R., Kreuzer, M., Hummel, J., Hatt, J.-M., Clauss, M., 2011. Intake, selection, digesta retention, digestion and gut fill of two coprophageous species, rabbits (Oryctolagus cuniculus) and guinea pigs (Cavia porcellus), on a hay-only diet. J. Anim. Physiol. Anim. Nutr. 95, 564-570.

Freudenberger, D.O., Hume, I.D., 1992. Ingestive and digestive responses to dietary fibre and nitrogen by two macropodid marsupials (Macropus robustus erubescens and M. r. robustus) and a ruminant (Capra hircus). Aust. J. Zool. 40, 181-194.

Gross, J.E., Alkon, P.U., Demment, M.W., 1996. Nutritional ecology of dimorphic herbivores: digestion and passage rates in Nubian ibex. Oecologia 107, 170-178.

Hackenberger, M.K., 1987. Diet digestibilities and ingesta transit times of captive Asian and African elephants. MSc Thesis. University of Guelph, Guelph.

Hammond, K.A., Wunder, B.A., 1991. The role of diet quality and energy need in the nutritional ecology of a small herbivore (Microtus ochrogaster). Physiol. Zool. 64, 541-567.

Holand, O., 1994. Seasonal dynamics of digestion in relation to diet quality and intake in European roe deer (Capreolus capreolus). Oecologia 98, $274-279$.

Holleman, D.F., White, R.G., 1989. Determination of digesta fill and passage rate from non absorbed particulate phase markers using the single dosing method. Can. J. Zool. 67, 488-494.

Hume, I.D., Morgan, K.R., Kenagy, G.J., 1993. Digesta retention and digestive performance in sciurid and microtine rodents: effects of hindgut morphology and body size. Physiol. Zool. 66, 396411.

Hummel, J., Clauss, M., Zimmermann, W., Johanson, K., Norgaard, C., Pfeffer, E., 2005. Fluid and particle retention in captive okapi (Okapia johnstoni). Comp. Biochem. Physiol. A 140, 436-444.

Hummel, J., Pfeffer, E., Norgaard, C., Johanson, K., Clauss, M., Nogge, G., 2006. Energetic nutrition of the okapi in captivity: intake and digestion trials. Zoo Biol. 25, 303-316.

Jiang, Z., Hudson, R.J., 1996. Digestive responses of wapiti to seasonal forages. Acta Theriol. 41, 415-425.

Karasov, W.H., Petrossian, E., Rosenberg, L., Diamond, J.M., 1986. How do food passage rate and assimilation differ between herbivorous lizards and nonruminants mammals? J. Comp. Physiol. B 156, 599-609.

Kennedy, P.M., McSweeney, C.S., Welch, J.G., 1992. Influence of dietary particle size on intake, digestion, and passage rate of digesta in goats and sheep fed wheaten (Triticum aestivum) hay. Small Rum. Res. 9, 125-138.

Luginbuhl, J.M., Pond, K.R., Burns, J.C., 1990. Physical limits to ruminal escape: experiences with the blue duiker, in: O.T. Oftedal, P.S. Barboza (Eds.), Digestive strategies of animals, a symposium. National Zoological Park, Smithsonian Institution, Washington DC, 10-11.

Luginbuhl, J.M., Pond, K.R., Burns, J.C., 1994. Whole-tract digesta kinetics and comparison of techniques for the estimation of fecal output in steers fed coastal bermudagrass hay at four levels of intake. J. Anim. Sci. 72, 201-211.

Mathers, J.C., Baber, R.P., Archibald, R.F., 1989. Intake, digestion and gastro-intestinal mean retention time in Asiatic buffaloes and Ayrshire cattle given two contrasting diets and housed at $20^{\circ}$ and $33^{\circ}$ C. J. Agric. Sci. $113,211-222$.

McIntosh, D.L., 1966. The digestibility of two roughages and the rates of passage of their residues by the red kangaroo and the merino sheep. CSIRO Wildl. Res. 11, 125-135.

Moore-Colyer, M.J.S., Morrow, H.J., Longland, A.C., 2003. Mathematical modelling of digesta passage rate, mean retention time and in vivo apparent digestibility of two different lengths of hay and big-bale grass silage in ponies. Br. J. Nutr. 90, 109-118.

Munn, A.J., Dawson, T.J., 2006. Forage fibre digestion, rates of feed passage and gut fill in juvenile and adult red kangaroos (Macropus rufus): why body size matters. J. Exp. Biol. 209, 1535-1547.

Nijboer, J., Clauss, M., Van de Put, K., Van der Kuilen, J., Wouterse, H., Beynen, A.C., 2007. Influence of two different diets on fluid and particle retention time in Javan langur (Trachypithecus auratus auratus). Zool. Garten NF 77, 36-46.

Norconk, M.A., Oftedal, O.T., Power, M.L., Jakubasz, M., Savage, A., 2002. Digesta passage and fiber digestibility in captive white-faced sakis (Pithecia pithecia). Am. J. Primatol. 58, 23-34.

Pagan, J.D. Harris, P., Brewster-Barnes, T., Duren, S.E., Jackson, S.G., 1998. Exercise affects digestibility and rate of passage of all-forage and mixed diets in thoroughbred horses. J. Nutr. 128 , 2704S-2707S.

Pearson, R.A., Merritt, J.B., 1991. Intake, digestion and gastrointestinal transit time in resting donkeys and ponies and exercised donkeys given ad libitum hay and straw diets. Equine Vet. J. 23, 339-343.

Pearson, R.A., Archibald, R.F., Muirhead, R.H., 2001. The effect of forage quality and level of feeding on digestibility and gastrointestinal transit time of oat straw and alfalfa given to ponies and donkeys. Br. J. Nutr. 85, 599-606

Pearson, R.A., Archibald, R.F., Muirhead, R.H., 2006. A comparison of the effect of forge type and level of feeding on the digestibility and gastrointestinal mean retention time of dry forages given to cattle, sheep, ponies and donkeys. Br. J. Nutr. 95, 88-98.

Pei, Y.X., Wang, D.H., Hume, I.D., 2001a. Selective digesta retention and coprophagy in Brandt's vole (Microtus brandti). J. Comp. Physiol. B 171, 457-464. 
Pei, Y.X., Wang, D.H., Hume, I.D., 2001b. Effects of dietary fibre on digesta passage, nutrient digestibility, and gastrointestinal tract morphology in the granivorous Mongolian gerbil (Meriones unguiculatus). Physiol. Biochem. Zool. 74, 742-749.

Remis, M.J., Dierenfeld, E.S., 2004. Digesta passage, digestibility and behavior in captive gorillas under two dietary regimes. Int. J. Primatol. 25, 825-845.

Sakaguchi, E., Itoh, H., Uchida, S., Horigome, T. 1987. Comparison of fibre digestion and digesta retention time between rabbits, guinea-pigs, rats and hamsters. Br. J. Nutr. 58, 149-158.

Sakaguchi, E., Hume, I.D., 1990. Digesta retention and fibre digestion in brushtail possums, ringtail possums and rabbits. Comp. Biochem. Physiol. A 96, 351-354.

Sakaguchi, E., Kaizu, K., Nakamichi, M., 1992a. Fibre digestion and digesta retention from different physical forms of the feed in the rabbit. Comp. Biochem. Physiol. A 102, 559-563.

Sakaguchi, E., Nabata, A., 1992. Comparison of fibre digestion and digesta retention time between nutrias and guinea-pigs. Comp. Biochem. Physiol. A 103, 601-604.

Sakaguchi, E., Nippashi, K., Endoh, G., 1992b. Digesta retention and fibre digestion in maras (Dolichotis patagonium) and guinea-pigs. Comp. Biochem. Physiol. A 101, 867-870.

Sakaguchi, E., Ohmura, S., 1992. Fibre digestion and digesta retention time in guinea-pigs, degus and leaf-eared mice. Comp. Biochem. Physiol. A 103, 787-791.

Schaefer, A.L., Young, B.A., Chimwano, A.M., 1978. Ration digestion and retention times of digesta in domestic cattle (Bos taurus), American bison (Bison bison), and Tibetan yak (Bos grunniens). Can. J. Zool. 56, 2355-2358.

Schaub, D., 2005. Der Einfluss von Futterrationen mit unterschiedlichen physikalischen Eigenschaften auf Futteraufnahme, Verhalten und weitere verdauungsphysiologische Parameter bei Giraffen (Giraffa camelopardalis). Diss. thesis, University of Zurich. Abteilung für Zoo-, Heim- und Wildtiere, Vetsuisse Fakultät.

Schwarm, A., Ortmann, S., Wolf, C., Streich, W.J., Clauss, M., 2008. Excretion patterns of fluids and particle passage markers of different size in banteng (Bos javanicus) and pygmy hippopotamus (Hexaprotodon liberiensis): two functionally different foregut fermenters. Comp. Biochem. Physiol. A 150, 32-39.

Schwarm, A., Ortmann, S., Wolf, C., Streich, W.J., Clauss, M., 2009a. Passage marker excretion in red kangaroo (Macropus rufus), collared peccary (Pecari tajacu) and colobine monkeys (Colobus angolensis, C. polykomos, Trachypithecus johnii). J. Exp. Zool. A 311, 647-661

Schwarm, A., Ortmann, S., Wolf, C., Streich, W.J., Clauss, M., 2009b. More efficient mastication allows increasing intake without compromising digestibility or necessitating a larger gut: comparative feeding trials in banteng (Bos javanicus) and pygmy hippopotamus (Hexaprotodon liberiensis). Comp. Biochem. Physiol. A 152, 504-512.

Steuer, P., Clauss, M., Südekum, K.-H., Hatt, J.-M., Silinski, S., Klomburg, S., Zimmermann, W., Hummel, J., 2010. Comparative investigations on digestion in grazing (Ceratotherium simum) and browsing (Diceros bicornis) rhinoceroses. Comp. Biochem. Physiol. A 156, 380-388.

Udén, P., Rounsaville, T.R., Wiggans, G.R., Van Soest, P.J., 1982. The measurement of liquid and solid digesta retention in ruminants, equines and rabbits given timothy (Phleum pratense) hay. Br. J. Nutr. 48, 329-339.

Udén, P., Van Soest, P.J., 1982. Comparative digestion of timothy fiber by ruminants, equines and rabbits. Br. J. Nutr. 47, 267-272.

Whetsell, M.S., Prigge, E.C., Nestor, E.L., 2004. Influence of mass of ruminal contents on voluntary intake and digesta passage in steers fed a forage and a concentrate diet. J. Anim. Sci. 82, 18061817.

Woodall, P.F., 1989. The effects of increased dietary cellulose on the anatomy, physiology and behaviour of captive water voles (Arvicola terrestris). Comp. Biochem. Physiol. A 94, 615-621. 